ARTICLE

\title{
Zinc regulates a key transcriptional pathway for epileptogenesis via metal-regulatory transcription factor 1
}

Karen M.J. van Loo', Christina Schaub ${ }^{2,3}$, Julika Pitsch¹, Rebecca Kulbida1, Thoralf Opitz², Dana Ekstein ${ }^{4,5}$, Adam Dalal ${ }^{4}$, Horst Urbach ${ }^{6}$, Heinz Beck ${ }^{2}$, Yoel Yaari ${ }^{4}$, Susanne Schoch ${ }^{1} \&$ Albert J. Becker ${ }^{1}$

Temporal lobe epilepsy (TLE) is the most common focal seizure disorder in adults. In many patients, transient brain insults, including status epilepticus (SE), are followed by a latent period of epileptogenesis, preceding the emergence of clinical seizures. In experimental animals, transcriptional upregulation of Cav3.2 T-type $\mathrm{Ca}^{2+}$-channels, resulting in an increased propensity for burst discharges of hippocampal neurons, is an important trigger for epileptogenesis. Here we provide evidence that the metal-regulatory transcription factor 1 (MTF1) mediates the increase of Cav3.2 mRNA and intrinsic excitability consequent to a rise in intracellular $\mathrm{Zn}^{2+}$ that is associated with SE. Adeno-associated viral (rAAV) transfer of MTF1 into murine hippocampi leads to increased Cav3.2 mRNA. Conversely, rAAV-mediated expression of a dominant-negative MTF1 abolishes SE-induced Cav3.2 mRNA upregulation and attenuates epileptogenesis. Finally, data from resected human hippocampi surgically treated for pharmacoresistant TLE support the $\mathrm{Zn}^{2+}$-MTF1-Cav3.2 cascade, thus providing new vistas for preventing and treating TLE.

\footnotetext{
${ }^{1}$ Section for Translational Epilepsy Research, Department of Neuropathology, University of Bonn Medical Center, Bonn 53105, Germany. ${ }^{2}$ Laboratory for Experimental Epileptology and Cognition Research, Department of Epileptology, University of Bonn Medical Center, Bonn 53105, Germany. ${ }^{3}$ Department of Neurology, University of Bonn Medical Center, Bonn 53105, Germany. ${ }^{4}$ Department of Medical Neurobiology, IMRIC, Hebrew University-Hadassah School of Medicine, Jerusalem 91120, Israel. ${ }^{5}$ Department of Neurology, Hadassah-Hebrew University Medical Center, Jerusalem 91120, Israel. ${ }^{6}$ Department of Neuroradiology, Medical Center University of Freiburg, Freiburg 79106, Germany. Correspondence and requests for materials should be addressed to A.J.B. (email: albert_becker@uni-bonn.de).
} 
E pilepsy affects $1 \%$ of individuals of all ages, socioeconomic backgrounds and races, and is the second most common cause of mental disability, particularly among young adults, accounting for a worldwide disease burden similar to that of breast cancer in women and lung cancer in $\operatorname{men}^{1-3}$. Chronic recurrent seizures often originate in the temporal lobe (temporal lobe epilepsy (TLE)) and are pharmacoresistant in approximately a third of the patients. Surgical removal of the epileptic focus, albeit highly effective, represents a therapy option for only a fraction of patients ${ }^{4}$. Often, TLE develops as a consequence of a brain disease or of an acute brain insult (acquired or 'symptomatic' TLE) via a multifaceted process referred to as epileptogenesis ${ }^{5}$. Intriguingly, a single episode of status epilepticus (SE) can induce the structural and functional alterations that lead to the emergence of chronic recurrent seizures. Identifying the key epileptogenic mechanisms is essential for devising new treatments to prevent or attenuate the development of TLE.

Recent experimental and clinical evidence suggests that acquired 'transcriptional channelopathies' play a role in epileptogenesis, as well as in the pathogenesis of other neurological disorders $^{6-9}$. Thus, in rodents, SE induced chemically with pilocarpine (pilocarpine-SE) causes a marked increase in the propensity for intrinsic bursting in hippocampal CA1 pyramidal cells, particularly in the early phase of epileptogenesis ${ }^{10}$. Pharmacological analyses with subtype-selective blockers of voltage-dependent $\mathrm{Ca}^{2}+$ channels (VDCCs) disclosed the involvement of a $\mathrm{Ni}^{2+}$-sensitive-T-type $\mathrm{Ca}^{2+}$ current $\left(I_{\mathrm{CaT}}\right)$ in this aberrant activity ${ }^{11,12}$. Congruently, $I_{\mathrm{CaT}}$ was threefold upregulated early after SE, whereas other $\mathrm{Ca}^{2}+$ currents were unchanged or even reduced ${ }^{12}$. Furthermore, a significant upregulation of $\mathrm{Ca}_{\mathrm{V}} 3.2$ mRNA, but not that of other T-type $\mathrm{Ca}^{2+}$-channel $\alpha_{1}$ mRNAs, was present in SE-experienced neurons and translated to an increase in $\mathrm{Ca}_{\mathrm{v}} 3.2$ protein level ${ }^{13}$. Interestingly, the emergence of epileptic seizures was strongly attenuated in $C a_{V} 3.2$ knockout mice subjected to pilocarpine$\mathrm{SE}^{13}$, indicating that transcriptional $\mathrm{Ca}_{\mathrm{V}} 3.2$ upregulation may play a pivotal role in epileptogenesis.

It has been shown that SE causes a rise in intracellular free $\mathrm{Zn}^{2+}$ concentrations $\left(\left[\mathrm{Zn}^{2+}\right]_{\mathrm{i}}\right)$ in pyramidal cells ${ }^{14}$ and we have recently demonstrated that $\mathrm{Zn}^{2+}$, although acutely and reversibly blocking T-type channels ${ }^{15}$, induces a long-term upregulation of $I_{\mathrm{CaT}}$ in hippocampal pyramidal cells in vivo ${ }^{16}$. Therefore, we have aimed at delineating the signalling cascade linking the increase in $\left[\mathrm{Zn}^{2+}\right]_{\mathrm{i}}$ to $C a_{V} 3.2$ promoter activation. Our results in vitro indicate that this link is mediated by metalregulatory transcription factor 1 (MTF1). Supporting data obtained from 'viral transgenic' mice and human TLE hippocampi suggest that MTF1 may be a target for treatment strategies aimed at impeding the development of epilepsy following acute brain insults.

\section{Results}

Selective induction of $\mathrm{Ca}_{\mathrm{v}} 3.2$ expression by $\mathrm{Zn}^{2+}$. To unravel the signalling cascades underlying $\mathrm{Zn}^{2+}$-induced $I_{\mathrm{CaT}}$ upregulation, we first examined the effect of elevating intracellular $\mathrm{Zn}^{2+}$ $\left(\left[\mathrm{Zn}^{2+}\right]_{\mathrm{i}}\right)$ on VDCC gene expression in neural NG108-15 cells. A large increase in $\left[\mathrm{Zn}^{2+}\right]_{\mathrm{i}}$ was triggered by incubating the cells

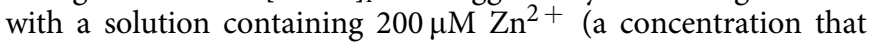
can be reached in pathological conditions such as ischemia, seizures and brain trauma $\left.{ }^{17}\right)$ and high $\mathrm{K}^{+}(50 \mathrm{mM}$ to depolarize the cells ${ }^{18,19}$ ). Only this combination (further referred to as $\mathrm{K}^{+}+\mathrm{Zn}^{2+}$ ), but not with $\mathrm{K}^{+}$or $\mathrm{Zn}^{2+}$ solutions alone, caused an increase in $\left[\mathrm{Zn}^{2+}\right]_{\mathrm{i}}$ (Fig. 1a,b). None of these treatments affected cell viability (Fig. 1c).
Next, we analysed the mRNA expression levels of the neuronal L-type $\left(\mathrm{Ca}_{\mathrm{V}} 1.2\right.$ and $\left.\mathrm{Ca}_{\mathrm{V}} 1.3\right), \mathrm{P} / \mathrm{Q}$-type $\left(\mathrm{Ca}_{\mathrm{V}} 2.1\right)$, N-type (Ca 2.2$)$, R-type $\left(\mathrm{Ca}_{\mathrm{V}} 2.3\right)$ and T-type $\left(\mathrm{Ca}_{\mathrm{V}} 3.1, \mathrm{Ca}_{\mathrm{V}} 3.2\right.$ and $\left.\mathrm{Ca}_{\mathrm{V}} 3.3\right)$ VDCCs in NG108-15 cells incubated with basal, $\mathrm{K}^{+}$or $\mathrm{K}^{+}+\mathrm{Zn}^{2+}$ solutions. In basal condition, high expression levels were obtained for $\mathrm{Ca}_{\mathrm{V}} 3.2$ and to a lesser degree for $\mathrm{Ca}_{\mathrm{V}} 2.2$ and $\mathrm{Ca}_{\mathrm{V}} 3.3$ (Fig. 1d). Incubation with $\mathrm{K}^{+}+\mathrm{Zn}^{2}$ solution resulted in a significant upregulation of $\mathrm{Ca}_{\mathrm{V}} 3.2$ mRNA levels, but did not affect mRNA levels of other VDCCs that are sensitive to block by submolar concentrations of $\mathrm{Ni}^{2}+$ (Fig. 1e, Supplementary Fig. 1). Furthermore, incubating NG108-15 cells with $\mathrm{K}^{+}$solutions containing other divalent cations $\left(0.5 \mathrm{mM} \mathrm{Ni}^{2+}\right.$ or $\left.1 \mathrm{mM} \mathrm{Cu}^{2+}\right)$ did not affect $\mathrm{Ca}_{\mathrm{V}} 3.2$ mRNA expression (Supplementary Fig. 2). Thus, a rise in $\left[\mathrm{Zn}^{2+}\right]_{i}$ uniquely and selectively enhances $\mathrm{Ca}_{\mathrm{V}} 3.2$ mRNA expression, an effect that is expected to cause an increase in $\mathrm{Ca}_{\mathrm{V}} 3.2$ protein level. Indeed, immunoblotting detected the $\mathrm{Ca}_{\mathrm{V}} 3.2$ protein under basal conditions and revealed a significant increase of $\mathrm{Ca}_{\mathrm{V}} 3.2$ protein levels after exposure of the cells to $\mathrm{K}^{+}+\mathrm{Zn}^{2+}$ solution (Fig. 1f,g).

Increase of $\boldsymbol{I}_{\text {CaT }}$ by $\mathbf{Z n}^{2+}$. We next used whole-cell patch-clamp recordings of $\mathrm{Ca}^{2+}$ currents in NG108-15 cells to investigate whether the $\mathrm{Zn}^{2+}$-induced increase in $\mathrm{Ca}_{\mathrm{V}} 3.2$ protein is reflected functionally in a larger $I_{\text {CaT }}$. NG108-15 cells were incubated in either $\mathrm{K}^{+}$or $\mathrm{K}^{+}+\mathrm{Zn}^{2+}$ solutions and $\mathrm{Ca}^{2+}$ currents were recorded. Representative examples of $I_{\mathrm{CaT}}$ in a control cell and in a cell exposed to $\mathrm{K}^{+}+\mathrm{Zn}^{2+}$ solution are shown in Fig. $2 \mathrm{a}$. We found that exposing the cells to $\mathrm{K}^{+}+\mathrm{Zn}^{2+}$ solution, but not to $\mathrm{K}^{+}$solution led to a significant increase in $I_{\mathrm{CaT}}$ (Fig. 2b,c). This increase was not accompanied by a change in voltage dependence of activation or inactivation (Fig. 2d, Supplementary Table 1). Expectedly, application of $100 \mu \mathrm{M} \mathrm{Ni}^{2+}$, a dose potently inhibiting $\mathrm{Ca}_{\mathrm{V}} 3.2$ channels (grey traces in Fig. 2e), almost completely reduced $I_{\mathrm{CaT}}$ in both basal and $\mathrm{K}^{+}+\mathrm{Zn}^{2+}$ conditions (Fig. 2f). Altogether, these findings are congruent with the notion that $\mathrm{Zn}^{2+}$-induced increase in $I_{\mathrm{CaT}}$ reflects an increase in functional $\mathrm{Ca}_{\mathrm{V}} 3.2$ channels.

$\mathrm{Zn}^{2+}$-induced activation of the $C \boldsymbol{a}_{V} 3.2$ promoter. We next sought to identify the molecular mechanisms underlying the $\mathrm{Zn}^{2+}$-induced upregulation of $\mathrm{Ca}_{\mathrm{v}} 3$ 3.2. To that end, we made use of the previously identified $C a_{V} 3.2$ promoter $^{20}$, the activity of which strongly correlates with endogenous $\mathrm{Ca}_{\mathrm{V}} 3.2$ mRNA levels. We found that treating the cells with $\mathrm{K}^{+}+\mathrm{Zn}^{2+}$ solution, but not with $\mathrm{K}^{+}$solution, resulted in a significant $C a_{V} 3.2$ promoter activation (Fig. 3a). This effect was enhanced by raising $\mathrm{Zn}^{2+}$ concentration above $200 \mu \mathrm{M}$. We further examined whether $\mathrm{Zn}^{2+}$-induced activation of the $C a_{V} 3.2$ promoter reverses on $\mathrm{Zn}^{2}+$ removal. To that end, we exposed cells having been incubated in a $\mathrm{K}^{+}+\mathrm{Zn}^{2+}$ solution to $\mathrm{N}, \mathrm{N}, \mathrm{N}^{\prime}, \mathrm{N}^{\prime}$-tetrakis (2-pyridylmethyl)ethane-1,2-diamine (TPEN), a cell permeable $\mathrm{Zn}^{2}+$ chelator. Intriguingly, TPEN significantly reduced $C a_{V} 3.2$ promoter activity. In contrast, basal activity of the $C a_{V} 3.2$ promoter was unaffected by TPEN (Fig. 3b). These data suggest that enhanced activation of the $C a_{V} 3.2$ promoter requires a sustained increase in $\left[\mathrm{Zn}^{2+}\right]_{i}$.

We next delineated the region responsible for $\mathrm{Zn}^{2+}$-induced $C a_{V} 3.2$ promoter activation by analysing $C a_{V} 3.2$ promoter deletion luciferase reporter constructs $\left(\mathrm{Ca}_{V} 3.2-1020,-312\right.$ and -105) (ref. 20). Increases in $\left[\mathrm{Zn}^{2+}\right]_{i}$ resulted in a significant $C a_{V} 3.2$ promoter activity only for the longest deletion fragment (Fig. 3c) suggesting that the $\mathrm{Zn}^{2+}$-responsive regulatory element is located in the genomic between 312 and 1,020 upstream of the $C a_{V} 3.2$ ATG. These findings indicate that $C a_{V} 3.2$ gene regulation is under control of a $\mathrm{Zn}^{2+}$-responsive 
a

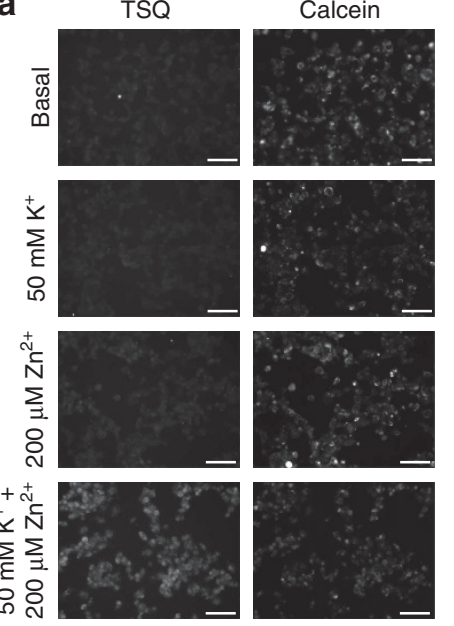

b
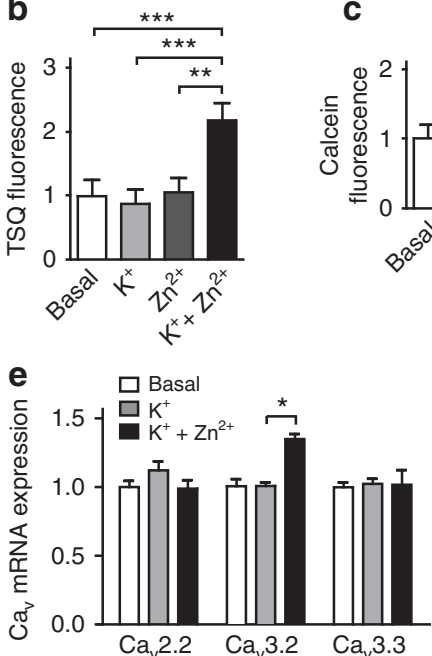

C

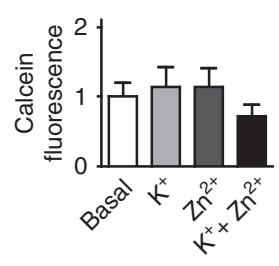

d

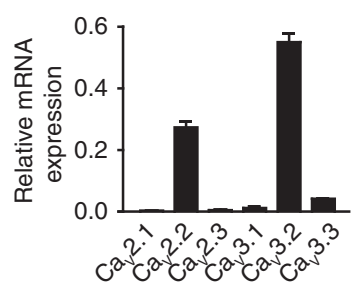

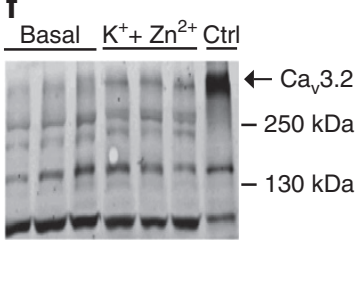

Figure $1 \mid \mathbf{Z n}^{2}+$ increases mRNA and protein expression levels of the T-type $\mathbf{C a}^{\mathbf{2}+}$-channel $\mathbf{C a} \mathbf{v}$ 3.2. (a) Representative images of the membranepermeant fluorescent $\mathrm{Zn}^{2}+$ indicator TSQ (left row) and calcein red-orange AM fluorescence (right row) in control NG108-15 cultures (basal) and after stimulation with $\mathrm{K}^{+}(50 \mathrm{mM}), \mathrm{Zn}^{2+}(200 \mu \mathrm{M})$ or $\mathrm{K}^{+}+\mathrm{Zn}^{2+}(50 \mathrm{mM} / 200 \mu \mathrm{M})$. Scale bar, $100 \mu \mathrm{m}$. (b) Quantification of TSQ and (c) calcein red-orange fluorescence after incubation with $\mathrm{K}^{+}, \mathrm{Zn}^{2+}$ or $\mathrm{K}^{+}+\mathrm{Zn}^{2+}$ normalized to control cultures (basal). Fluorescence intensity was quantified, background corrected for single cells and then averaged for every field of view. Normalization was performed for simultaneously treated and measured cultures ( $n=5$ in two independent experiments; ${ }^{\star \star} P \leq 0.01$; ${ }^{\star \star \star} P \leq 0.001$; repeated measures analysis of variance (ANOVA), multiple Bonferroni's multiple comparison test). (d) Relative mRNA expression of the voltage-dependent calcium channels in NG108-15 cells. Only Cav2.2, Cav3.2 and Cav3.3 are expressed above background levels. (e) Quantitative RT-PCR for Cav2.2, Cav3.2 and Cav3.3 mRNA levels in NG108-15 cells stimulated with $\mathrm{K}^{+}$or $\mathrm{K}^{+}+\mathrm{Zn}^{2+}$. mRNA expression was measured $4 \mathrm{~h}$ after stimulation, with synaptophysin as reference gene (one-way ANOVA: $P=0.0142 ; F_{(8,27)}=3.045$; Tukey's multiple comparisons test, $\left.{ }^{\star} P \leq 0.05 ; n=4\right)$. (f) Immunoblot for the $\sim 260 \mathrm{kDa}$ Cav3.2 protein in NG108-15 cells 3 days after incubation basal or $\mathrm{K}^{+}+\mathrm{Zn}^{2+}$ solutions $(50 \mathrm{mM} / 200 \mu \mathrm{M})$. As a control, HEK-293 cells stably expressing Cav3.2 were probed. (g) Quantification based on $\alpha$-tubulin levels ( $t$-test: $\left.{ }^{\star \star} P \leq 0.01 ; n=3\right)$.

transcription factor ${ }^{21}$. The only currently known transcription factor fulfilling these criteria in mammals is MTF1.

MTF1 increases $C a_{V} 3.2$ promoter activation and $I_{C a T}$. Subsequent bioinfomatic analyses revealed a surprising accumulation of potential binding sites (metal-responsive elements (MREs)) for MTF1 (Table 1$)^{22}$. One of the bioinformatically detected MREs resided within the above identified $\mathrm{Zn}^{2}+$-inducible minimal $C a_{V} 3.2$ promoter region (Fig. $4 \mathrm{a}$ ), supporting a role for MTF1 in the $\mathrm{Zn}^{2+}$-dependent $\mathrm{Ca}_{\mathrm{V}} 3.2$ mRNA expression. To test if MTF1 indeed is able to stimulate the $C a_{V} 3.2$ promoter, we analysed $C a_{V} 3.2$ promoter activity after MTF1 overexpression in NG108-15 cells and primary hippocampal neurons. Indeed, MTF1 overexpression increased $\mathrm{Ca}_{V} 3.2$ promoter activity in both cell types to similar levels as observed after stimulation with $\mathrm{K}^{+}+\mathrm{Zn}^{2+}$ (Fig. 4b). Whole-cell patch-clamp recordings revealed that overexpression of MTF1 in NG108-15 cells led to a substantial increase of $I_{\mathrm{CaT}}$ (Fig. 4c). These augmented currents were almost completely blocked by $100 \mu \mathrm{M} \mathrm{Ni}^{2+}$ (Fig. $4 \mathrm{~d}$ ), indicating that they are generated by $\mathrm{Ca}_{\mathrm{v}} 3.2$ subunits.

MTF1 binds a $\mathrm{Zn}^{2+}$-sensitive MRE in the $C a_{V} 3.2$ promoter. We then probed whether the $\mathrm{Zn}^{2+}$-inducible genomic fragment of the $C a_{v} 3.2$ promoter (Fig. $4 \mathrm{a}$ ) corresponds to the genomic region of the $C a_{v} 3.2$ promoter with maximal MTF1 responsiveness. We therefore analysed the activity of three $\mathrm{Ca}_{V} 3.2$ promoter deletion fragments in the presence of MTF1. Only the $C a_{V} 3.2$ promoter fragment harbouring the MRE located in the $\mathrm{Zn}^{2+}$ inducible region was activated by MTF1 overexpression (Fig. 5a). Subsequent mutation of this MRE significantly reduced the $C a_{V} 3.2$ promoter activity after MTF1 overexpression (Fig. 5b), indicating that this MRE is indeed responsible for the
MTF1-induced $\mathrm{Ca}_{V} 3.2$ upregulation. In addition, chromatin immunoprecipitation (ChIP) analysis of NG108-15 cells, as well as of mice hippocampi, revealed binding of MTF1 to the $\mathrm{Zn}^{2+}$. sensitive MRE in the $C a_{V} 3.2$ promoter region (Fig. 5c).

To prove unequivocally that the $\mathrm{Zn}^{2+}$-induced $C a_{V} 3.2$ promoter activation is mediated by MTF1, a dominant-negative form of MTF1 (MTF1 $\Delta \mathrm{C})^{23}$ was co-transfected with the $C a_{V} 3.2$ 1188 reporter plasmid. MTF1 $\Delta \mathrm{C}$ is still able to bind MREs but does not possess the ability to activate transcription, thereby blocking MREs from wild-type MTF1. Treatment with $\mathrm{K}^{+}+\mathrm{Zn}^{2+}$ solution of cells overexpressing MTF1 $\Delta \mathrm{C}$ resulted in a complete repression of $\mathrm{Zn}^{2+}$-induced $C a_{V} 3.2$ promoter activation (Fig. 5d). Therefore, MTF1 appears necessary and sufficient to mediate the stimulatory effects of $\mathrm{Zn}^{2+}$ on the $C a_{V} 3.2$ promoter.

MTF1 upregulates hippocampal $\mathrm{Ca}_{\mathrm{V}} 3.2 \mathrm{mRNA}$ in vivo. It was previously shown that pilocarpine-SE induces an increase in $\left[\mathrm{Zn}^{2+}\right]_{\mathrm{i}}$ in the somata of CA1 pyramidal cells ${ }^{14}$, likely due to the release of intracellularly bound $\mathrm{Zn}^{2}+$ (ref. 24). We investigated in rats the time course of this increase using TFL staining of hippocampal slices resected from control and SE-experienced animals (Fig. 6a; CA1, CA3, hilus and granular layer of the dentate gyrus). The strongest increase in TFL staining was observed in the CA1 region (Fig. 6b). TFL-positive pyramidal cells first appeared at 1 day after SE, their incidence peaking 2-4 days after SE and declining thereafter (Fig. 6b,c). These data suggest an association between the SE-induced rise in $\left[\mathrm{Zn}^{2+}\right]_{i}$ and the SE-induced increases in $\mathrm{Ca}_{\mathrm{V}} 3.2 \mathrm{mRNA}$ and protein, as well as in $I_{\mathrm{CaT}}$ (ref. 13). To test whether MTF1 mediates between the rise in $\left[\mathrm{Zn}^{2+}\right]_{\mathrm{i}}$ and associated increases in $\mathrm{Ca}_{\mathrm{V}} 3.2$ expression and function, we first transduced mice brains with MTF1. To that end, we injected either rAAV-CMV-MTF1-IRES-Venus (MTF1 

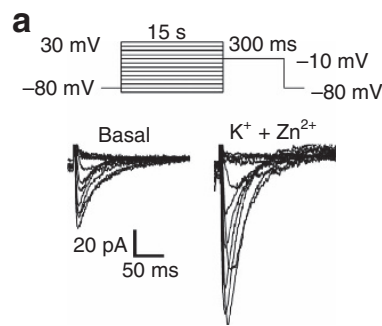

d

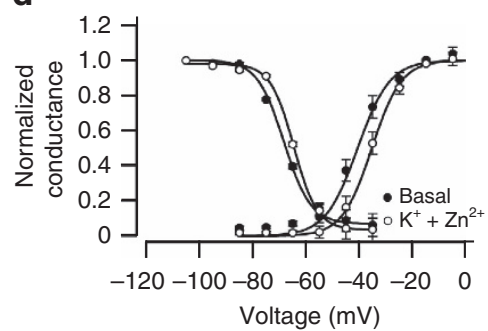

b

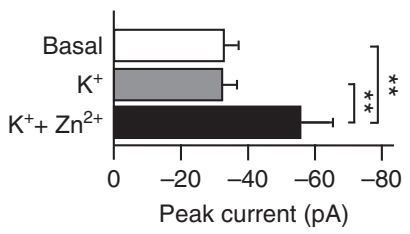

e
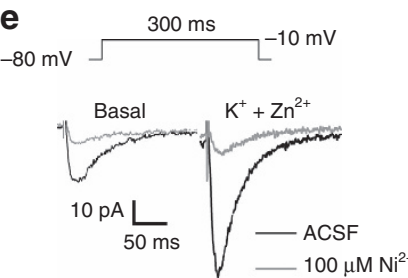

C
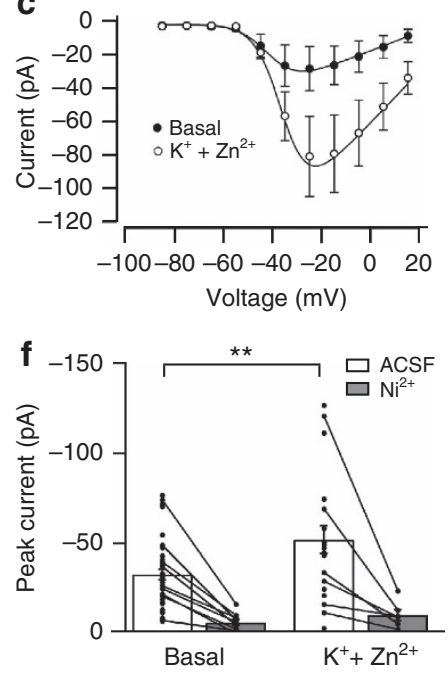

Figure 2 | Increase of the T-type current by $\mathbf{Z n}^{2}+$. (a) Analysis of $I_{\text {CaT }}$ of NG108-15 cells stimulated with $\mathrm{K}^{+}+\mathrm{Zn}^{2+}(50 \mathrm{mM} / 200 \mu \mathrm{M})$ for $4 \mathrm{~h}$, measured 1 day after stimulation. $\mathrm{Ca}^{2+}$ currents were recorded in the presence of $\mathrm{Na}^{+}$and $\mathrm{K}^{+}$current blockers (tetraethylammonium $20 \mathrm{mM}$, 4-AP $4 \mathrm{mM}$ and tetrodotoxin $1 \mu \mathrm{M}$ ). Cells were depolarized from a holding potential of $-80 \mathrm{mV}$ to various potentials ranging from -90 to $+30 \mathrm{mV}$, yielding transient, predominantly T-type $\mathrm{Ca}^{2}+$ currents. Representative current families elicited with the voltage protocol (upper panel) under basal conditions (left) and following increases in $\left[\mathrm{Zn}^{2+}\right]_{\mathrm{i}}$. (b) Quantification of the peak $I_{\mathrm{CaT}}$ elicited by a step to $-10 \mathrm{mV}$ under the different conditions; basal: $n=37$ cells; $\mathrm{K}^{+}: n=11$ cells; $\mathrm{K}^{+}+\mathrm{Zn}^{2+}: n=22$ cells; $t$-test: ${ }^{\star} \mathrm{P} \leq 0.01$ ). (c) Current-voltage relationship of T-type currents under basal conditions and following incubation with $\mathrm{K}^{+}+\mathrm{Zn}^{2+}$ (filled circles basal, $n=3$; open circles $\mathrm{K}^{+}+\mathrm{Zn}^{2+}, n=3$ ). (d) The voltage dependence of $I_{\text {CaT }}$ activation and inactivation was unaltered in cells treated with $\mathrm{K}^{+}+\mathrm{Zn}^{2+}$ compared with untreated controls (filled circles basal, activation $n=3$, inactivation $n=9$; open circles $\mathrm{K}^{+}+\mathrm{Zn}^{2+}$, activation $n=3$, inactivation $n=6$ ). (e) $\mathrm{Ca}^{2+}$ currents were elicited with a voltage step from -80 to $-10 \mathrm{mV}$ (upper part). Representative current traces show an increased amplitude in cells incubated with $\mathrm{K}^{+}+\mathrm{Zn}^{2+}$ (lower trace right) compared with cells under basal conditions (lower trace left). Representative current traces showed the potent block by $100 \mu \mathrm{M} \mathrm{Ni}^{2+}$, indicating involvement of Cav3.2 channels (grey trace). (f) Average of the transient $\mathrm{Ca}^{2+}$ current of all cells for control cells (basal, $\left.n=37\right)$ and cells incubated with $\mathrm{K}^{+}+\mathrm{Zn}^{2+}(n=22)$ display $I_{\text {CaT }}$ upregulation following incubation with $\mathrm{K}^{+}+\mathrm{Zn}^{2+}\left(t\right.$-test: $\left.{ }^{\star \star} P \leq 0.01\right)$. Average of the transient currents after application of $100 \mu \mathrm{M} \mathrm{Ni}{ }^{2+}$ showed a large amplitude reduction in all recorded cells $(-33.1 \pm 3.0 \mathrm{pA}, n=37$ versus $-6.5 \pm 1.7 \mathrm{pA}, n=9$ for basal conditions and $-52.2 \pm 7.8 \mathrm{pA}, n=22$ versus $-10.4 \pm 3.0 \mathrm{pA}, n=6$ following incubation with $\mathrm{K}^{+}+\mathrm{Zn}^{2+}$ ).
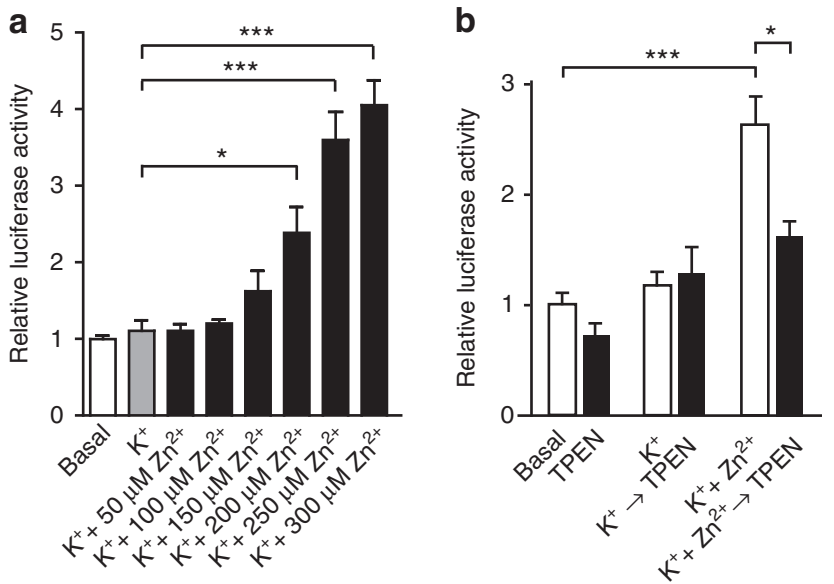

C

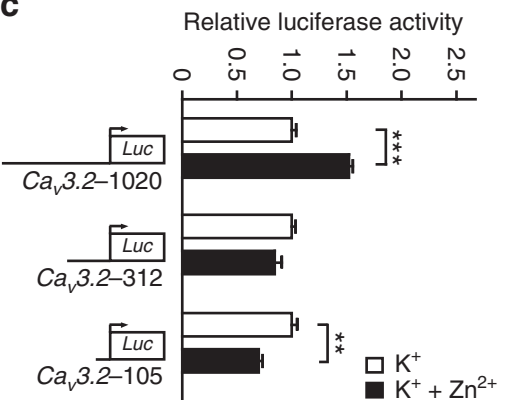

Figure 3 | Increases in $\left[\mathbf{Z n}^{\mathbf{2}+}\right]_{\mathbf{i}}$ activate the $\mathbf{C a}_{\mathbf{v}} \mathbf{3 . 2}$ promoter. (a) NG108-15 cells transfected with the 1,188-bp Cav3.2 promoter-luciferase reporter construct ${ }^{20}$ and stimulated with $\mathrm{K}^{+}+\mathrm{Zn}^{2+}$ in the presence of increasing $\mathrm{Zn}^{2+}$ concentrations $(0,50,100,150,200,250$ and $300 \mu \mathrm{M})$. The effect on the promoter activity was determined using a luciferase assay $4 \mathrm{~h}$ after stimulation (one-way analysis of variance $(\mathrm{ANOVA}): P<0.001 ; F_{(7,16)}=25.64 ;$ Tukey's multiple comparisons test, ${ }^{\star} P \leq 0.05,{ }^{\star \star \star} P \leq 0.001 ; n=3$ ). (b) Activity of the $C a_{V} 3.2$ promoter-luciferase reporter gene determined after stimulation of NG108-15 cells first with $\mathrm{K}^{+}$or $\mathrm{K}^{+}+\mathrm{Zn}^{2+}(50 \mathrm{mM} / 500 \mu \mathrm{M})$ solutions for $1 \mathrm{~h}$ and subsequently incubated in the presence or absence of TPEN (10 $\left.\mu \mathrm{M}\right)$ for $1 \mathrm{~h}$. Luciferase activity was measured $4 \mathrm{~h}$ after stimulation (one-way ANOVA: $P<0.001 ; F_{(5,10)}=24.63$; Tukey's multiple comparisons test, ${ }^{\star} P \leq 0.05$, $\left.{ }^{\star \star \star} P \leq 0.001 ; n \geq 3\right)$. (c) Luciferase activity of three $\mathrm{Ca}_{V} 3.2$ promoter deletion fragments ${ }^{20}$ after stimulation with $\mathrm{K}^{+}+\mathrm{Zn}^{2+}(50 \mathrm{mM} / 200 \mu \mathrm{M})$. Only the $\mathrm{Ca}_{V}$ 3.2-1020 deletion fragment showed significant activation of the $\mathrm{Ca}_{V} 3.2$ promoter after stimulation with $\mathrm{K}^{+}+\mathrm{Zn}^{2+}$. The short $\mathrm{Ca}_{V} 3.2-105$ showed a significantly reduced activity after stimulation with $\mathrm{K}^{+}+\mathrm{Zn}^{2+}$, likely due to the presence of $\mathrm{Zn}^{2+}$-inhibitory regions within this fragment (one-way ANOVA: $P<0.001 ; F_{(5,12)}=39.82$; Tukey's multiple comparisons test, ${ }^{\star \star} P \leq 0.01$, $\left.{ }^{\star \star} P \leq 0.001 ; n=3\right)$. 
group) or rAAV-CMV-Venus particles (control group) into area CA1 of mice hippocampi. The mRNA isolated from hippocampi of both groups revealed significantly increased MTF1 mRNA expression in the former group, indicating efficient viral transduction. Correspondingly, we observed $\mathrm{Ca}_{\mathrm{v}} 3.2 \mathrm{mRNA}$ expression to be significantly increased in the MTF1 group versus the control group (Fig. 6d). In addition, in vivo imaging using infrared fluorescent proteins (iRFP) under control of the $C a_{V} 3.2$ promoter (Fig. 6e,f) also showed the activation of the $\mathrm{Ca}_{V} 3.2$ promoter after transduction with MTF1 and a remarkably similar activation after intrahippocampal injection of $\mathrm{Zn}^{2+}$ (Fig. $6 \mathrm{~g}-\mathrm{j}$ ). These data thus show that MTF1 and $\mathrm{Zn}^{2+}$ activate the $C a_{V} 3.2$ promoter also in vivo.

We next similarly injected mice with MTF1 $\Delta \mathrm{C}$. We injected either rAAV-CMV-MTF1 $\Delta$ C-IRES-Venus (MTF1 $\Delta \mathrm{C}$ group) or rAAV-CMV-Venus particles (control group) into area CA1 of mice hippocampi (Fig. 7a). Two weeks after injection, mice were either subjected to pilocarpine-SE or sham treated. The mice were killed 3 days thereafter, that is, at the time point of maximal $\mathrm{Ca}_{\mathrm{V}} 3.2$ mRNA increase after $\mathrm{SE}^{13}$. Interestingly, overexpression of MTF1 $\Delta \mathrm{C}$ significantly reduced the SE-induced increase in $\mathrm{Ca}_{\mathrm{V}} 3.2$ mRNA peak during early epileptogenesis (Fig. 7b), further

Table 1 | MREs located within the $\mathrm{Ca}_{v} 3.2$ promoter region.

\begin{tabular}{llll} 
& Position & Orientation & Sequence \\
\hline 1 & $994 \mathrm{bp}$ & Forward sequence & TGCGCCC \\
2 & $275 \mathrm{bp}$ & Forward sequence & TGCGCGC \\
3 & $152 \mathrm{bp}$ & Reverse sequence & TGCGCCC \\
MRE-consensus sequence & & TGCRCNC \\
\hline
\end{tabular}

indicating that MTF1 mediates between the SE-induced rise in $\left[\mathrm{Zn}^{2+}\right]_{\mathrm{i}}$ and the transcriptional $\mathrm{Ca}_{\mathrm{v}} 3.2$ upregulation.

Given its key role in SE-induced $\mathrm{Ca}_{\mathrm{v}} 3.2$ transcription, we also studied whether pilocarpine-SE affects MTF1 expression levels. We found that the levels of MTF1 mRNA significantly increased 6 and $12 \mathrm{~h}$ after SE, and returned to basal values thereafter (Fig. 7c).

Interfering with MTF1 attenuates seizure development. We have previously shown that mice lacking $\mathrm{Ca}_{\mathrm{V}} 3.2$ manifested a much milder form of chronic TLE ${ }^{13}$. We therefore expected that interfering with the $\mathrm{Zn}^{2+}-\mathrm{MTF} 1-\mathrm{Ca}_{\mathrm{v}} 3.2$ cascade would also exert an antiepileptogenic action. We tested this prediction in mice transduced with MTF1 $\Delta \mathrm{C}$ as described above. With respect to the acute SE induced by pilocarpine, we found no differences in electroencephalography (EEG) recordings between MTF1 $\Delta \mathrm{C}$ mice and control animals before, during and after the SEs (Fig. 8a). Likewise, the two groups of mice were similar with respect to the latencies to the first acute seizure and to the onset of SE (Fig. 8b). These results show that the two groups of mice likely experience SEs of identical intensities. Further EEG monitoring indicated that spontaneous seizures emerged in both groups of mice (representative examples of EEGs shown in Fig. 8c). However, seizure frequency was substantially lower in MTF1 $\Delta C$ mice compared with control animals (Fig. 8d,e). Intriguingly, the extent of neurodegeneration found in MTF1 $\Delta \mathrm{C}$ mice was similar to that found in control animals, despite the lesser seizure frequency in the former group (Supplementary Fig. 3).

Increased MTF1 and Ca 3.2 expression correlate in HS. To assess the potential role of the $\mathrm{Zn}^{2+}-\mathrm{MTF} 1-\mathrm{Ca}_{\mathrm{V}} 3.2$ cascade in

a
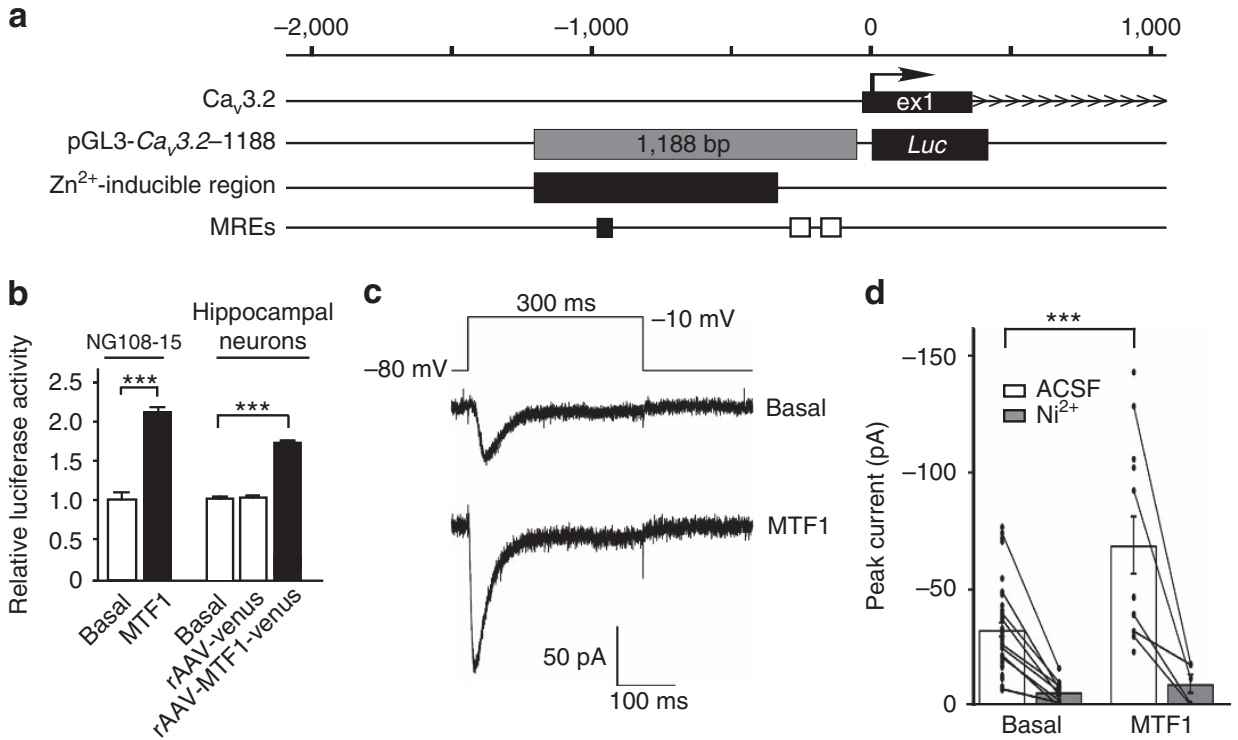

Figure 4 | MTF1 mediates the activation of $\mathbf{C a}_{\mathbf{v}} \mathbf{3 . 2}$ promoter by $\mathbf{Z n}^{\mathbf{2}+}$ and increases functional expression of Cav3.2. (a) Schematic overview of the rat $\mathrm{Ca}_{V} 3.2$ promoter region with the $\mathrm{Ca}_{V} 3.2-1188$ promoter-luciferase reporter construct ${ }^{20}$. The identified $\mathrm{Zn}^{2+}$-inducible region is indicated (black box) together with the three MREs. One MRE is located within the $\mathrm{Zn}^{2+}$-inducible region (black bar), whereas two MREs are located outside the $\mathrm{Zn}^{2+}$ inducible region (white bars). (b) Left panel: luciferase activity of the Cav3.2 promoter construct after transfection with MTF1 in NG108-15 cells. Right panel: luciferase activity of the $\mathrm{Ca}_{V} 3.2$ promoter in rat hippocampal neurons transduced with rAAV particles harbouring the rat $\mathrm{Ca}_{V} 3.2$ promoter luciferase reporter (rAAV-CaV3.2) (ref. 39), a pRL-TK control promoter construct, an expression construct for MTF1 (rAAV-CMV-MTF1-IRES-Venus) or a control expression construct (rAAV-CMV-Venus) at DIV1 and measured at DIV15 ( $t$-test: ${ }^{\star \star \star} P \leq 0.001 ; n=3$ ). (c) $C a^{2+}$ currents in NG108-15 cells were elicited with a voltage step from -80 to $-10 \mathrm{mV}$ (upper part). Representative current traces show an increased amplitude in MTF1-transfected cells (lower trace) compared with controls (upper trace). (d) Average of the transient $\mathrm{Ca}^{2}+$ currents for control cells $(n=37)$ and cells transfected with MTF1 ( $\left.n=12\right)$ display the functional upregulation of T-type $\mathrm{Ca}^{2+}$ currents ( $t$-test: $\left.{ }^{\star \star \star} P \leq 0.001\right)$. Average of the transient currents after application of $100 \mu \mathrm{M} \mathrm{Ni}{ }^{2+}$ showed the large amplitude reduction in all recorded cells ( $n=9$ for basal conditions and $n=5$ following $\mathrm{Zn}^{2}+$ application), indicating involvement of Cav 3.2 channels. 
a

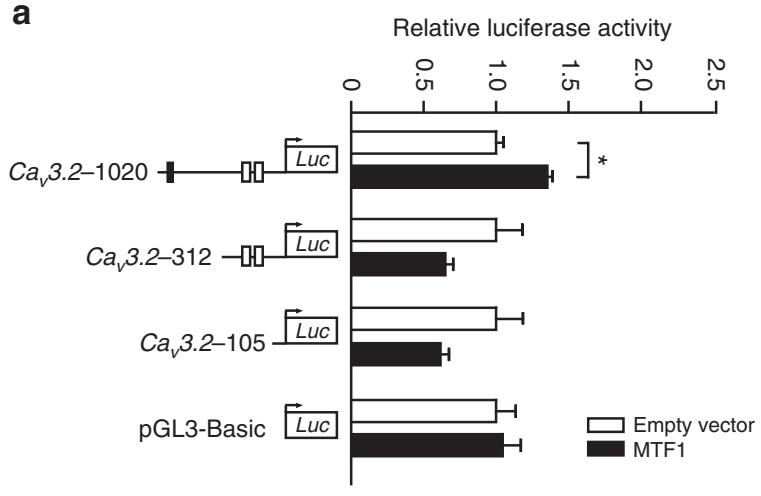

C

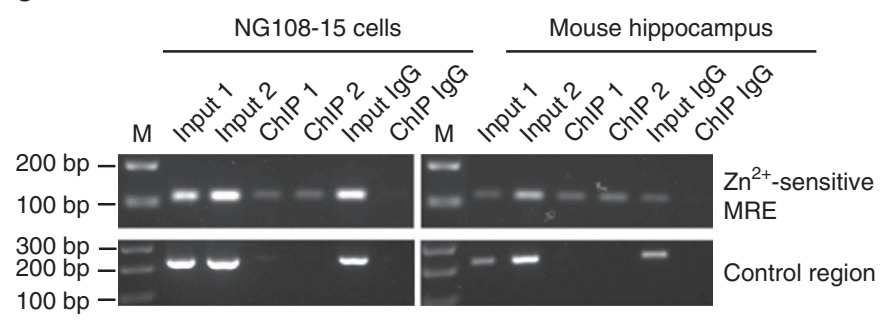

b

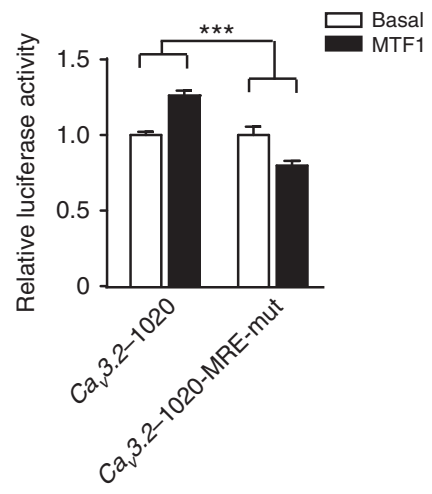

d

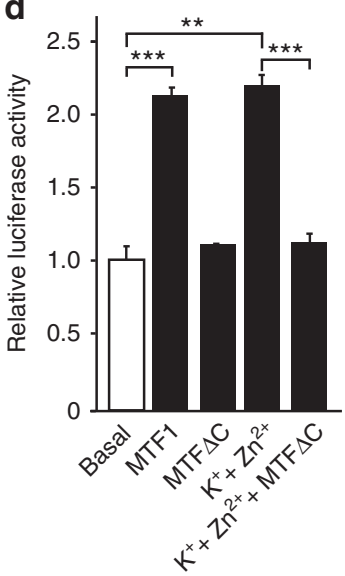

Figure 5 | MTF1 binds the $\mathbf{C a}_{\boldsymbol{v}} \mathbf{3 . 2}$ promoter. (a) Luciferase activity of the Cav3.2 promoter deletion fragments after overexpression with MTF1. Note the almost similar activation pattern of the Cav3.2 promoter deletion fragments as seen after stimulation with $\mathrm{K}^{+}+\mathrm{Zn}^{2+}(50 \mathrm{mM} / 200 \mu \mathrm{M}$; Fig. $3 \mathrm{c})$. No activation was observed for the pGL3-basic control plasmid (one-way analysis of variance (ANOVA): $P=0.012 ; F_{(7,16)}=3.856$; Tukey's multiple comparisons test, ${ }^{\star} P \leq 0.05 ; n=3$ ). (b) Luciferase activity of the $C a_{V} 3.2-1020$ fragment and the $C a_{V} 3.2-1020$ fragment with the mutated $\mathrm{Zn}^{2+}{ }_{- \text {-sensitive }}$ MRE-binding site ( $\left.\mathrm{Ca}_{V} 3.2-1020-\mathrm{MRE}-\mathrm{mut}\right)$ after overexpression with MTF1. Mutation of the $\mathrm{Zn}^{2+}$-sensitive MRE-binding site resulted in a reduced Cav3.2 promoter activity (two-way ANOVA: $P=0.0002 ; F_{(1,8)}=38.9$. (c) ChIP analysis of MTF1 binding to the $\mathrm{Zn}^{2+}$-sensitive MRE within the Cav3.2 promoter. PCR amplicons were generated of anti-MTF1 ChIP immunoprecipitates from NG108-15 cells and mouse hippocampi, using primer pairs spanning the Zn ${ }^{2+}$. sensitive MRE and a control region in the Cav3.2 promoter lacking a MRE. A rabbit-lgG immunoprecipitate was used as negative control. (d) Luciferase activity of unstimulated and $\mathrm{K}^{+}+\mathrm{Zn}^{2+}$-challenged $(50 \mathrm{mM} / 200 \mu \mathrm{M}) \mathrm{NG} 108-15$ cells transfected with the full-length Ca 3.2 promoter-luciferase reporter construct and MTF1 or MTF1 $\triangle C$ (one-way ANOVA: $P<0.001 ; F_{(4,10)}=117.9$; Tukey's multiple comparisons test, ${ }^{\star \star} P \leq 0.01,{ }^{\star \star \star} P \leq 0.001 ; n \geq 3$ ).

human TLE, we analysed hippocampal MTF1 and $\mathrm{Ca}_{\mathrm{V}} 3.2$ expression levels in pharmacoresistant TLE patients with hippocampal sclerosis (HS) versus patients with 'lesion-associated' TLE (Supplementary Note 1). We found a strong positive correlation between MTF1 and $\mathrm{Ca}_{\mathrm{V}} 3.2$ expression levels in both groups of patients (Fig. 9b, Supplementary Fig. 4). These data indicate that the correlation of expression between MTF1 and $\mathrm{Ca}_{\mathrm{v}} 3.2$ is a rather stable phenomenon, especially when considering patients heterogeneity with respect to endophenotypes (for example, hippocampal damage, time point after seizure onset, etc.) and genetic background. Intriguingly, both MTF1 and $\mathrm{Ca}_{\mathrm{v}} 3.2 \mathrm{mRNA}$ expression levels were substantially higher in TLE patients with HS compared with those with 'lesion-associated' TLE (Fig. 9c). This difference may reflect differences in seizure frequencies or intensities between the two groups or in other factors regulating $\left[\mathrm{Zn}^{2+}\right]_{\mathrm{i}}$.

\section{Discussion}

Here we describe a novel mechanism of neuronal plasticity, which we refer to as the $\mathrm{Zn}^{2+}{ }_{-} \mathrm{MTF} 1-\mathrm{Ca}_{\mathrm{V}} 3.2$ cascade, wherein a rise in $\left[\mathrm{Zn}^{2+}\right]_{\mathrm{i}}$ activates MTF1, which then binds to MREs in the $C a_{V} 3.2$ gene promoter and increases transcription of this gene. The increase in $\mathrm{Ca}_{\mathrm{V}} 3.2$ mRNA leads to enhanced expression of $\mathrm{Ca}_{\mathrm{V}} 3.2$ channels and larger $I_{\mathrm{CaT}}$. In CA1 pyramidal cells, the $I_{\mathrm{CaT}}$ increase causes regular firing cells to convert to burst firing, thereby enhancing the excitability of the hippocampal network ${ }^{10,11}$. Our cumulative data suggest that this cascade may play a pivotal role in epileptogenesis triggered by pilocarpine-SE. First, pilocarpineSE leads to a rise in $\left[\mathrm{Zn}^{2+}\right]_{\mathrm{i}}$ in CA1 pyramidal cells, appearing within a day and persisting for at least 1 week. Second, exposure of cells to elevated $\left[\mathrm{Zn}^{2+}\right]_{\mathrm{i}}$ induces transcriptional upregulation of $\mathrm{Ca}_{\mathrm{V}} 3.2$ mediated by MTF1. Third, pilocarpine-SE causes a selective increase in $I_{\mathrm{CaT}}$ in CA1 pyramidal cells ${ }^{12}$ that is underlain by transcriptional upregulation of $\mathrm{Ca}_{\mathrm{V}} 3.2$ (ref. 13). This increase is temporally correlated with the rise in $\left[\mathrm{Zn}^{2+}\right]_{i}$ and is reduced by transfection of these neurons with MTF1 $\Delta \mathrm{C}$ (shown to interfere with $\mathrm{Zn}^{2+}$-induced $\mathrm{Ca}_{\mathrm{V}} 3.2$ mRNA upregulation), suggesting a causal relationship between the two SE-induced effects. Finally, deletion of $\mathrm{Ca}_{\mathrm{V}} 3.2$ markedly attenuates the emergence of recurrent seizures following pilocarpine-SE ${ }^{13}$, and this antiepileptogenic effect is mimicked by transfecting the hippocampi with MTF1 $\Delta \mathrm{C}$. Thus, the development of chronic TLE in the pilocarpine-SE model may be attenuated by targeting 
a

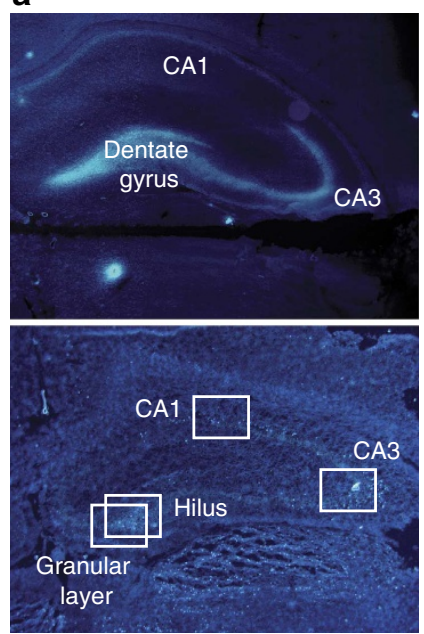

b

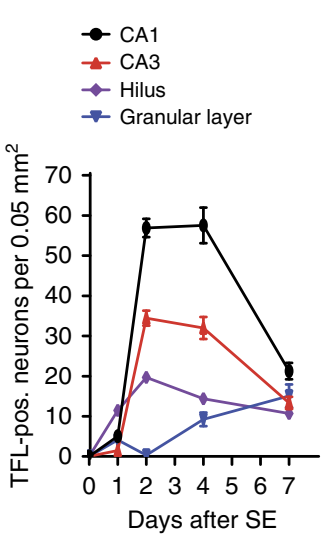

c

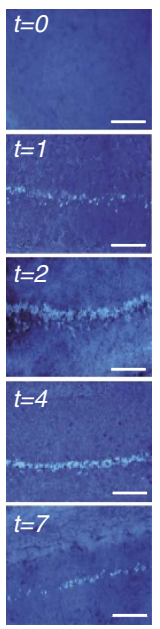

d

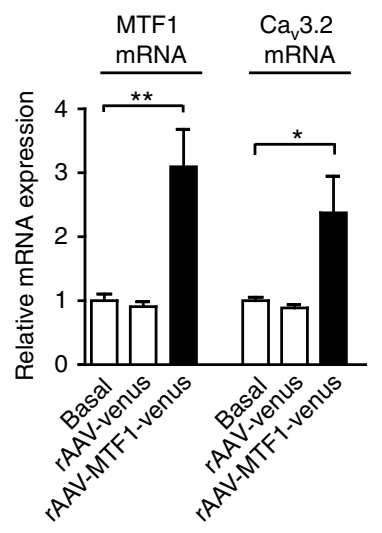

e

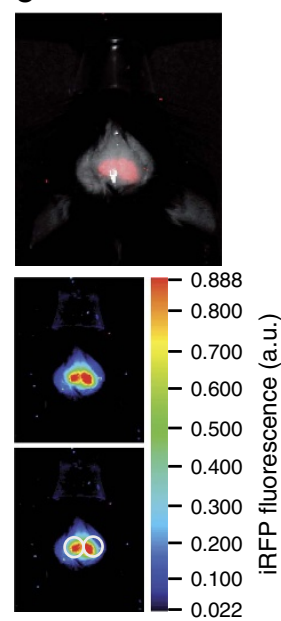

f

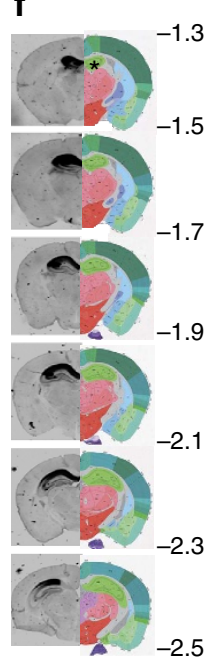

g
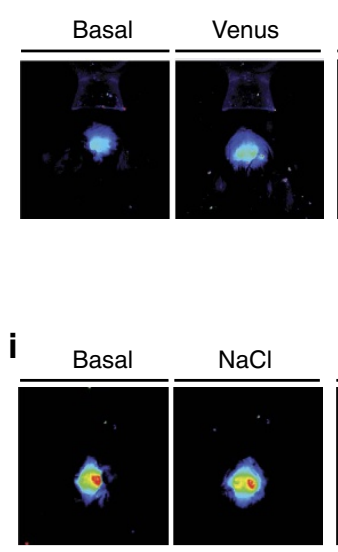

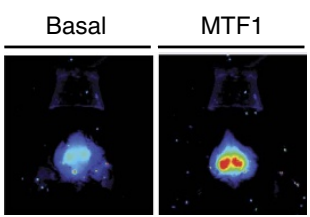

h
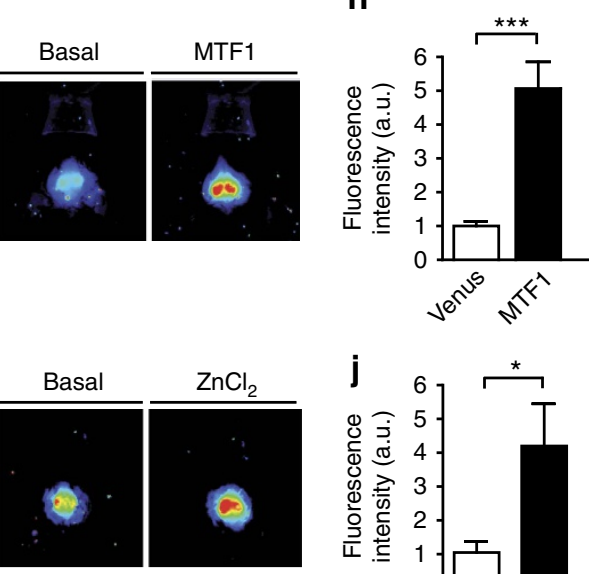

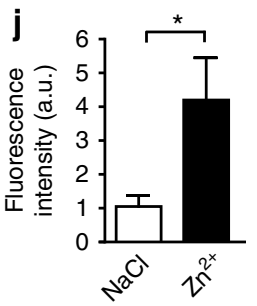

Figure 6 | The $\mathrm{Zn}^{2+}$-MTF1-Cav3.2 cascade contributes to Cav3.2 upregulation. (a) TFL-Zn ${ }^{2+}$ staining of the hippocampal region in the pilocarpine-SE model in rats under basal conditions (upper panel) and 2 days after SE (lower panel). White boxes represent the grids for differential counting in four distinct areas (CA1, CA3, hilus and the granular layer of the dentate gyrus (DG)). (b) Quantification of TFL-positive neurons in hippocampal CA1, CA3 and DG at various time points after SE ( $n=3$ rats per time point; 39 slices). (c) Representative examples of TFL- $\mathrm{Zn}^{2+}$ staining in the CA1 area under basal conditions and 1, 2, 4 and 7 days after SE. Scale bar, $50 \mu \mathrm{m}$. (d) Quantitative RT-PCR on total hippocampi isolated from control, rAAV-Venus and rAAVMTF1-Venus-injected mice. Expression levels were measured 14 days after injection, with synaptophysin as reference gene (one-way analysis of variance: $P<0.001 ; F_{(5,18)}=12.32$; Tukey's multiple comparisons test, $\left.{ }^{\star} P \leq 0.05,{ }^{\star}{ }^{\star} P \leq 0.01 ; n=3\right)$. (e) Near-infrared in vivo imaging. Upper panel: representative example of in vivo iRFP signal of a recorded mouse with exposed skull. Middle panel: pseudo colour visualization of iRFP signals. Lower panel: regions of interest (ROIs) were defined above the hippocampal region and the surface radiance was defined in arbitrary units (a.u.). The colour bar indicates the total fluorescence efficiency. (f) iRFP fluorescence of coronal brain slices isolated from a rAAV-Cav3.2-iRFP-injected animal (left side: iRFP fluorescence intensity; right side: reference images from the Allen Mouse Brain Atlas (@2015 Allen Institute for Brain Science: http://mouse.brain-map.org), with the hippocampal region annotated with an asterisk (upper panel). Positions (in $\mathrm{mm}$ ) are given relative to Bregma. (g) Representative example of a recorded rAAV-Cav3.2-iRFP mouse under basal conditions and 3 weeks after injection with rAAV-Syn-Venus (Venus) or rAAV-Syn-MTF1-IRES-Venus (MTF1).

(h) Quantification of iRFP signals of rAAV-Syn-Venus $(n=10)$ - and rAAV-Syn-MTF1-IRES-Venus $(n=10)$-injected animals $\left(t\right.$-test: $\left.{ }^{\star \star \star} P \leq 0.001\right)$.

(i) Representative example of a recorded $\mathrm{rAAV}$ - $\mathrm{Ca}_{V} 3.2$-iRFP mouse under basal conditions and 3 days after injection with $1 \mu \mathrm{l} 0.9 \% \mathrm{NaCl}$ or $1 \mu \mathrm{l} 100 \mu \mathrm{M}$ $\mathrm{ZnCl}_{2}$. (j) Quantification of iRFP signals of $\mathrm{NaCl}(n=8)$ - and $\mathrm{ZnCl}_{2}(n=8)$-injected animals ( $t$-test: $\left.{ }^{*} P \leq 0.05\right)$.

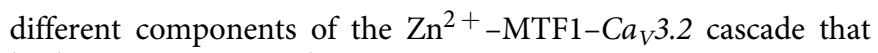
lead to $\mathrm{Ca}_{\mathrm{v}} 3.2$ upregulation.

We found that $\left[\mathrm{Zn}^{2+}\right]_{\mathrm{i}}$ increases, acting via MTF1, upregulate $C a_{V} 3.2$ promoter activity but do not affect transcription of other T-type $\mathrm{Ca}^{2+}$ channel subunits. This intriguing selectivity is due to the fact that only $\mathrm{Ca}_{\mathrm{V}} 3.2$, but not $\mathrm{Ca}_{\mathrm{V}} 3.1$ and $\mathrm{Ca}_{\mathrm{V}} 3.3$, contain MREs in the $1.5-\mathrm{kb}$ genomic region upstream of the start ATG. Indeed, gene promoters that harbour MREs are sparsely distributed throughout mammalian genomes ${ }^{25}$. The only ones known to be regulated by MTF1 in a $\left[\mathrm{Zn}^{2+}\right]_{\mathrm{i}}$-dependent manner are the genes encoding for metallothioneins. These are small, cysteine-rich proteins with a high affinity for $\mathrm{Zn}^{2}+$ and other heavy metals ${ }^{26}$. By increasing the expression of metallothioneins, MTF1 acts in a negative feedback manner to facilitate removal of excess free $\mathrm{Zn}^{2+}$ (ref. 27).

In the pilocarpine-SE model, deleting $C a_{V} 3.2$ not only reduced the frequency of recurrent seizures in the chronic stage but also strongly protected the hippocampus from SE-induced neurodegeneration $^{13}$. Here we show that transducing hippocampi with $\mathrm{MTF} 1 \Delta \mathrm{C}$ also reduced chronic seizures frequency, but did not 
a

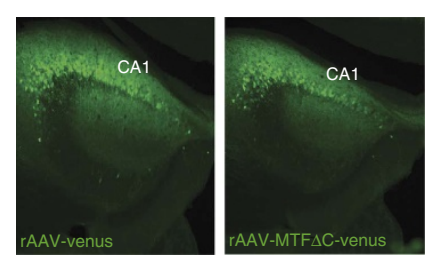

b

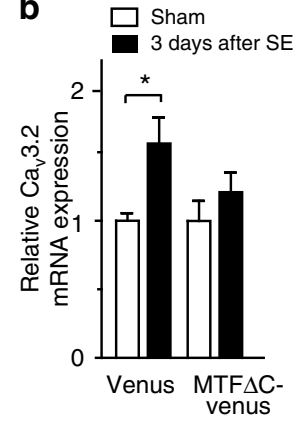

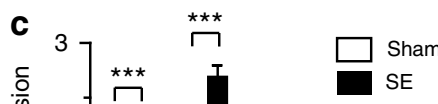

Figure 7 | The $\mathbf{Z n}^{2}+$-MTF1-Cav3.2 cascade in the pilocarpine-SE model. (a) Representative image of a rAAV-Venus- and rAAV-MTF1 $\Delta C$-Venus-injected animal. (b) mRNA expression of Cav3.2 in mice injected with rAAV-Venus (left) and rAAV-MTF1 $\triangle C$-Venus (right) 3 days after pilocarpine-induced SE (quantification based on synaptophysin; one-way analysis of variance (ANOVA): $P=0.0335 ; F_{(3,26)}=3.374$; Tukey's multiple comparisons test, ${ }^{\star} P \leq 0.05$; $n=4)$. (c) MTF1 mRNA expression of hippocampal CA1 6, 12, 24, 36 and $72 \mathrm{~h}$ after pilocarpine-induced SE in mice (quantification based on synaptophysin; one-way ANOVA: $P<0.001 ; F_{(9,39)}=21.71 ;$ Tukey's multiple comparisons test, $\left.{ }^{\star \star \star} P \leq 0.001 ; n \geq 4\right)$.

a

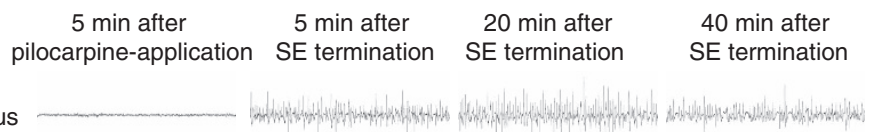

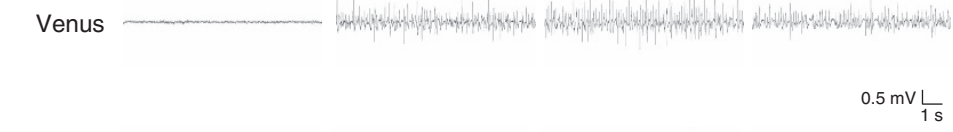
MTF $\Delta$ Cvenus

C

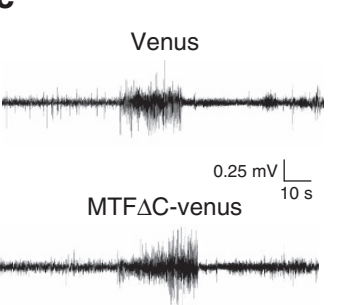

d

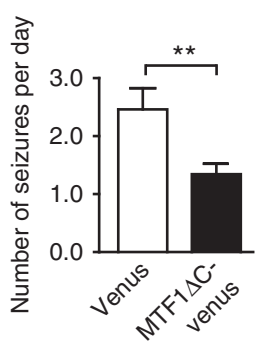

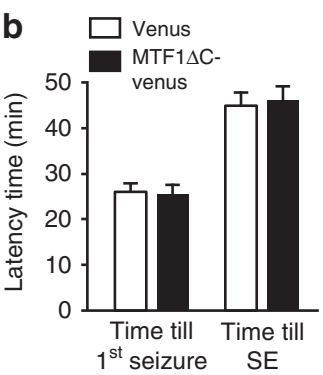

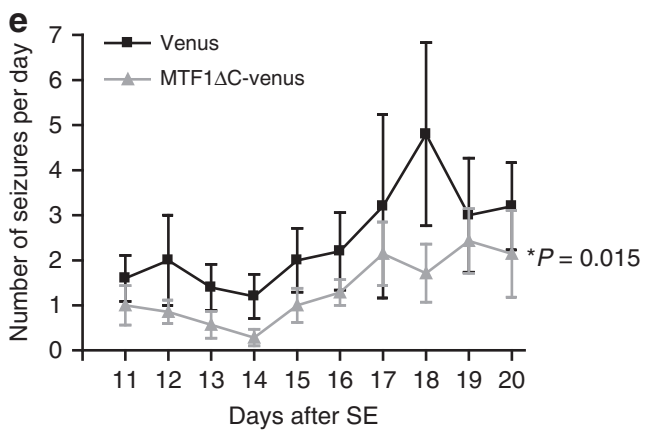

Figure 8 | Emergence of spontaneous seizures is markedly attenuated in animals transduced with MTF1 $\triangle$ C. (a) Representative EEG traces of a $r A A V$ Venus- and rAAV-MTF1 $\triangle$ C-Venus-injected animal 5 min after pilocarpine application and 5, 20 and 40 min after SE onset. (b) No differences for the latency to first seizure (left) and latency to SE (right) in animals injected with rAAV-MTF1 $\Delta$ C-Venus $(n=7)$ compared with animals injected with rAAVVenus $(n=5)$. (c) Representative EEG recordings from SE-experienced rAAV-Venus- and rAAV-MTF1 $\Delta C$-Venus-injected animals. (d) Average number of seizures in the chronic epileptic stage in rAAV-Venus- $(n=5)$ and rAAV-MTF1 $\Delta C$-Venus-injected animals $\left(n=7 ; t\right.$-test: $\left.{ }^{\star \star} P \leq 0.01\right)$. (e) Spontaneous seizure activity after SE in rAAV-Venus versus rAAV-MTF1 $\triangle C$-Venus animals. The frequency of spontaneous seizures is significantly decreased in rAAVMTF1 $\Delta$ C-Venus $(n=5)$ versus rAAV-Venus animals $\left(n=7 ; t\right.$-test: $\left.{ }^{\star} P \leq 0.05\right)$.

prevent neurodegeneration. This discrepancy may be due to the fact that MTF1 $\triangle \mathrm{C}$ overexpression also interferes with MTF1mediated upregulation of metallothioneins, thereby allowing $\left[\mathrm{Zn}^{2+}\right]_{\mathrm{i}}$ to increase to toxic levels. To overcome this side effect, and to unequivocally prove that the reduction of seizures after treatment with MTF1 $\Delta \mathrm{C}$ is due to a direct effect on the $C a_{V} 3.2$ promoter, the $\mathrm{Zn}^{2+}$-sensitive MRE in the $C a_{V} 3.2$ promoter could be genetically modified in vivo using the CRISPR/Cas complex ${ }^{28}$. Subsequent analysis of these mice in the pilocarpine-SE model will then reveal whether they experience less seizure activity as well as a reduced neurodegeneration.

Our findings suggest that pilocarpine-SE evokes the $\mathrm{Zn}^{2+}$ MTF1-Ca 3.2 cascade by inducing a rise in $\left[\mathrm{Zn}^{2+}\right]_{\mathrm{i}}$. However, the mechanism coupling SE to $\left[\mathrm{Zn}^{2}+\right]_{\mathrm{i}}$ increase is yet unknown. During the intense neuronal activity underlying SE, labile $\mathrm{Zn}^{2+}$ is released from glutamatergic terminals and may enter postsynaptic neurons via multiple routes ${ }^{14}$. Alternatively, $\mathrm{Zn}^{2+}$ tightly bound to metallothioneins may be released by action of nitric oxide ${ }^{29,30}$, whose production is markedly increased during $\mathrm{SE}^{31}$. In either case, another potential strategy to impede the $\mathrm{Zn}^{2+}-\mathrm{MTF} 1-\mathrm{Ca}_{\mathrm{V}} 3.2$ cascade would be the early application of cell permeable $\mathrm{Zn}^{2+}$ chelators. However, given that $\mathrm{Zn}^{2+}$ is mandatory for many critical cell processes ${ }^{32}$, its chelation might lead to deleterious effects ${ }^{33}$. An alternative strategy to impede the $\mathrm{Zn}^{2+}-\mathrm{MTF} 1-\mathrm{Ca}_{\mathrm{V}} 3.2$ cascade would be to interfere with nitric oxide accumulation by application of nitric oxide synthase inhibitors or scavengers. Pharmacological targeting of $\mathrm{Ca}_{\mathrm{V}} 3.2$ blockers early after pilocarpine-SE may also prove to be antiepileptogenic, and selective $\mathrm{Ca}_{\mathrm{V}} 3.2$ blockers are becoming available ${ }^{4}$. Alternatively, MTF1 may be targeted pharmacologically. The fact that activation and promoter binding of MTF1 require phosphorylation ${ }^{23,35}$ may enhance the 
a

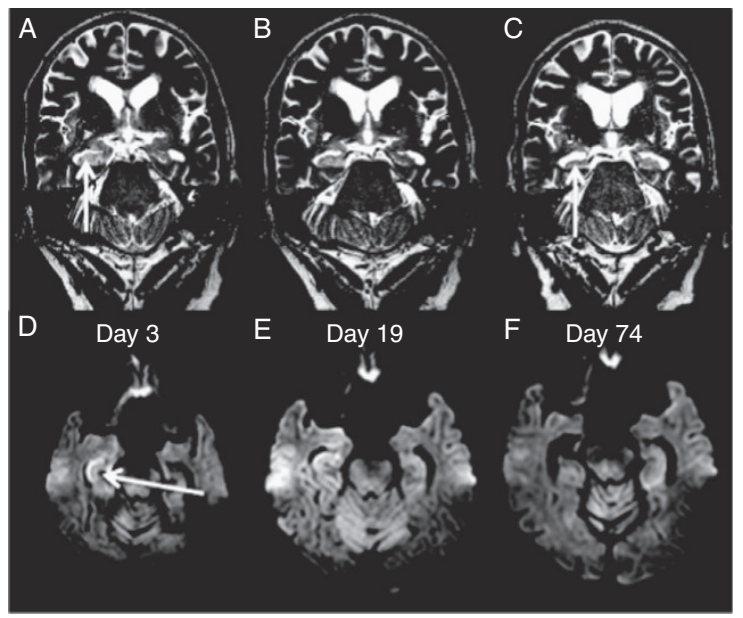

b
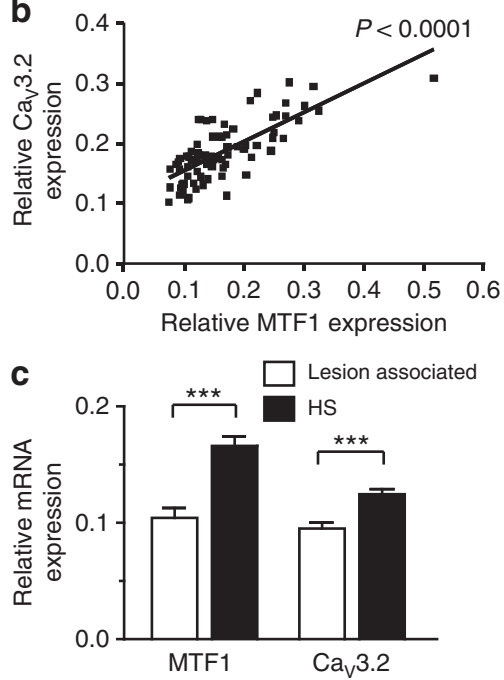

Figure 9 | MTF1 and Cav3.2 expression levels co-segregate and are increased in hippocampal tissue of patients with HS. (a) Epileptogenesis in a human individual without any previous neurological symptoms. The patient initially manifested clinically with SE (Supplementary Note 2). Coronal T2weighted fast spin echo $(\mathrm{A}-\mathrm{C})$ and axial diffusion-weighted spin echo planar imaging (EPI) show the rapid development of a right-sided HS in the clinical course. Initially, there is hippocampal swelling (A: arrow) associated with cytotoxic oedema of the CA1 sector (D: arrow). Two weeks later, swelling and cytotoxic oedema are somewhat regredient but still present (B,E). Only 8 weeks later, cytotoxic oedema has disappeared (F) and hippocampal atrophy, that is, HS has manifested (C: arrow). MNI (Montreal Neurological Institute) coordinates as derived from the 'standard brain template' correspond to 30 , -14 and 20. (b) Regression analyses of Cav3.2 mRNA versus MTF1 mRNA expression in patients with HS. A strong positive correlation between the two variables is present even in the heterogeneous group of human HS hippocampi. (c) Quantitative determination of MTF1 and Cav3.2 mRNA. MTF1 and Cav3.2 are significantly abundant expressed in hippocampal tissue of TLE patients with HS versus hippocampi from patients with lesion-associated TLE, that is, in which seizures are explained by lesions such as low-grade neoplasms and/or focal dysplasia in the immediate vicinity or even including the hippocampal formation (HS: $n=79$; lesion associated: $n=35$; $t$-test: ${ }^{\star \star \star} P \leq 0.001$, with synaptophysin as reference gene).

development of inhibitory drugs, for example, by small molecule library screening ${ }^{36}$. As perspective, we suggest that pharmacological interventions targeting the $\mathrm{Zn}^{2}{ }_{-M T F 1-}$ $\mathrm{Ca}_{\mathrm{V}} 3.2$ cascade may prove as intriguing future option for treating pharmacoresistant TLE.

\section{Methods}

Bioinformatic analysis and plasmids. MREs were identified using the software tool PoSSuMsearch ${ }^{37}$ with position-specific scoring matrices from the TRANSFAC database ${ }^{38}$.

The mammalian expression vectors pCDNA3-HA-mMTF1 and pCDNA3MTF1-EcoRl (dominant negative; MTF1 $\Delta$ C) were kindly provided by Carl Seguin (Québec) and Guy J. Rosnan (Fred Hutchinson Cancer Center, Seattle).

The $C a_{V}$ 3.2-1020-MRE-mut reporter plasmid was made by mutating the $\mathrm{Zn}^{2+}$. sensitive MRE in the $C a_{V} 3.2-1020$ luciferase promoter fragment ${ }^{20}$. For this, the first three nucleotides of the MRE consensus sequence (TGC; Table 1) were mutated into GAG, resulting in a destroyed MRE. Mutagenesis was performed using the QuikChange II XL Site-Directed Mutagenesis Kit (Agilent Technologies, Waldbronn, Germany) with the following primers: 5'-CACTGCGGGGGCCTCGA GCCGGCGGGG-3' and $5^{\prime}$-CCCCGCCGGCTCGAGGCCCCCGCAGTG-3' , and with conditions as follows: $2 \mathrm{~min}$ at $95^{\circ} \mathrm{C}$, then 18 cycles of $50 \mathrm{~s}$ at $95^{\circ} \mathrm{C}, 50 \mathrm{~s}$ at $55^{\circ} \mathrm{C}$ and $10 \mathrm{~min}$ at $68^{\circ} \mathrm{C}$.

For construction of the adeno-associated viral (AAV) plasmids, pAAV-CMVMCS harbouring the AAV2 inverted terminal repeats (Stratagene, La Jolla, USA) was modified. For pAAV-CMV-MTF1-IRES-Venus, first an IRES-Venus sequence was cloned in the SalI and BglII sites of pAAV-CMV-MCS. The MTF1 sequence was amplified from pCDNA3-HA-mMTF1 using primers with Bsu15I and BglII overhang and cloned in the Bsu15I and BamHI digested pAAV-CMV-IRES-Venus vector, resulting in pAAV-CMV-MTF1-IRES-Venus. For pAAV-CMV-Venus, a sequence encoding the green fluorescent protein Venus was inserted in the HindIII and BglII sites of pAAV-CMV-MCS. The pAAV-hSyn-Venus construct was made from pAAV-CMV-Venus by exchange of the promoters via the MluI and Bsu15I sites. The pAAV-hSyn-MTF1C-IRES-Venus construct was made from pAAVCMV-IRES-Venus by exchange of the CMV with hSynapsin promoter (MluI and EcoRI) and introducing MTF1 $\Delta \mathrm{C}$ (EcoRI and BglII/BamHI).

The pAAV-Ca 3 3.2-luciferase construct has been described previously ${ }^{39}$. For the AAV-RL-TK control plasmid, the RL-TK cassette (Promega, Mannheim, Germany) was amplified with NotI overhang and cloned in NotI-digested pAAV-MCS. The pAAV-Ca $3 \cdot 2-\mathrm{iRFP}^{713}$ was made by exchanging the luciferase from pAAV-Ca 3 3.2-venus with $\mathrm{iRFP}^{713}$ (Addgene clone \#31857) using HindIII and BglII restriction sites. All AAV-cloning procedures were performed in Stbl2 bacteria (Life Technologies, Germany) to minimize recombination events. Plasmid sequences were verified by sequencing analysis. Integrity of the inverted terminal repeats was confirmed by SmaI restriction analysis.

Cell cultures. Several types of cultured cells were used in this study. NG108-15 cells (American Type Culture Collection HB-12317) were maintained at $37^{\circ} \mathrm{C}$ and $5 \% \mathrm{CO}_{2}$ in DMEM supplemented with $10 \%(\mathrm{v} / \mathrm{v})$ heat-inactivated FCS (Invitrogen) 100 units per $\mathrm{ml}$ penicillin/streptomycin, $2 \mathrm{mM}$ glutamine and $1 \times$ HAT (sodium hypoxanthine, aminopterin and thymidine; Invitrogen). If not stated otherwise,

NG108-15 cells were seeded in 24-well plates with 60,000 cells per well. HEK293 cells stably transfected with human $\mathrm{Ca}_{\mathrm{V}} 3.2$ (kindly provided by Ed Perez-Reyes, University of Virginia, Charlottesville, VA, USA) and HEK293-AAV cells (\#240073, Stratagene, La Jolla, CA) were kept in high-glucose DMEM supplemented with $10 \%$ FCS (Invitrogen), 100 units per ml penicillin/streptomycin and $2 \mathrm{mM}$ glutamine, and incubated at $37^{\circ} \mathrm{C}$ and $5 \% \mathrm{CO}_{2}$. Primary rat hippocampal neurons were prepared and kept in culture as described previously ${ }^{40}$.

$\mathbf{Z n}^{\mathbf{2}}+$ loading of NG108-15 cells. Twenty-four hours after seeding, NG108-15 cells were loaded for $30 \mathrm{~min}$ with calcein red-orange AM $(2.5 \mu \mathrm{g}$ per well; Invitrogen Molecular Probes). Next, the cells were incubated for $4 \mathrm{~h}$ with one of the following solutions: (i) basal solution containing (in $\mathrm{mM}$ ): $\mathrm{NaCl}, 140 ; \mathrm{KCl}, 3$; $\mathrm{CaCl}_{2}, 2 ; \mathrm{MgCl}_{2}, 1$; D-glucose, 25; HEPES/NaOH, 10 (pH 7.4); (ii) $\mathrm{K}^{+}$solution, same as the basal solution but $\mathrm{KCl}$ concentration raised to $50 \mathrm{mM}$; (iii) $\mathrm{Zn}^{2+}$ solution, same as the basal solution but with added $\mathrm{Zn}^{2}+(200 \mu \mathrm{M})$; and (iv) $\mathrm{K}^{+}+\mathrm{Zn}^{2+}$ solution, same as the $\mathrm{K}^{+}$solution but containing also $200 \mu \mathrm{M}$ $\mathrm{Zn}^{2+}$. Fifteen minutes after returning the cells to the DMEM incubation medium they were exposed to the fluorescent $\mathrm{Zn}^{2}+$ indicator $N$-(6-methoxy-8-quinolyl)- $p$ toluenesulfonamide (TSQ; $0.001 \%$ final, added from $0.5 \%$ weight per volume stock in dimethylsulfoxide). Ten minutes later, cells were examined and photographed under a fluorescence microscope (Axio Observer.A1, Zeiss). Photographs $(\times 20)$ were taken under identical conditions. Background-corrected calcein red-orange and TSQ fluorescence was quantified for single cells (regions of interest were set using a differential interference contrast image) using Image software (NIH) and averaged for every field of view.

mRNA isolation and real-time RT-PCR quantification. mRNA from NG108-15 cell preparations and hippocampi was isolated using the Dynabeads mRNA Direct Micro Kit (Invitrogen) according to the manufacturer's protocol. cDNA was 
synthesized by reverse transcription from total RNA using the RevertAid Premium First strand cDNA Synthesis Kit (Fermentas) following the manufacturer's protocol. $\mathrm{Ca}^{2+}$ channel subunit transcript quantification was performed by realtime reverse transcription-PCR (RT-PCR). Relative quantification of the starting mRNA copy numbers was carried out according to the $\Delta \Delta C_{\mathrm{t}}$ method. The signal threshold was set within the exponential phase of the reaction for determination of the threshold cycle $\left(C_{\mathrm{t}}\right)$. PCR samples contained $1 \times$ Maxima Probe/ROX qPCR Master Mix (Fermentas), $5 \mathrm{pM}$ each oligonucleotide primer (Supplementary Table 2 ) and $1 / 10$ synthesized cDNA in a $6.25-\mu \mathrm{l}$ volume. Quantitative PCR was performed in an ABI Prism 7900HT apparatus (PE Applied Biosystems, Foster City, CA, USA) with conditions as follows: $2 \mathrm{~min}$ at $50^{\circ} \mathrm{C}, 10 \mathrm{~min}$ at $95^{\circ} \mathrm{C}$, then 40 cycles of $15 \mathrm{~s}$ at $95^{\circ} \mathrm{C}$ and $1 \mathrm{~min}$ at $59^{\circ} \mathrm{C}$.

Western blot analysis. For western blot analysis, cells were washed with ice-cold PBS, detached from the plates and centrifuged for $1 \mathrm{~min}$ at $4^{\circ} \mathrm{C}$. Pellets were resuspended in PBS $+10 \mathrm{mM}$ EDTA and homogenized by sonification. Proteins were quantified using the nanodrop (ThermoScientific) and $150 \mu \mathrm{g}$ protein was loaded on 7\% Tris-glycine SDS-PAGE gels and transferred to nitrocellulose membranes. Membranes were blocked for $1 \mathrm{~h}$ at room temperature in $2 \%$ fish gelatin (Sigma) and then incubated for $1 \mathrm{~h}$ with antibodies directed against $\mathrm{Ca}_{\mathrm{V}} 3.2$ (1:200; cat \#: ACC-025; Alomone Labs) and $\alpha$-tubulin (1:10,000; ab7291; Abcam). After washing and an hour incubation with the secondary antibodies (IRDye680 goat-anti-rabbit and IRDye800 goat-anti-mouse; both 1:20,000; LI-COR) in PBS $+0.1 \%$ Tween 20, immunoreactive bands were detected using the Odyssey infrared imaging system (Li-COR Biosciences GmbH, Bad Homburg, Germany) and quantified using the AIDA software (Raytest). The $\alpha$-tubulin signal was used as internal control. Full blots are shown in Supplementary Fig. 5.

Electrophysiology. Patch-clamp recordings were obtained from NG108-15 cells. One day after stimulation, cells were washed, trypsinized, seeded on coverslips and measured $4 \mathrm{~h}$ after seeding. Patch pipettes (3-4M $)$ were fabricated from borosilicate glass capillaries and filled with an intracellular solution containing (in $\mathrm{mM}$ ): CsF, 110; tetraethylammonium chloride, $20 ; \mathrm{MgCl}_{2}$, 2; HEPES, 10; EGTA, 11; ATP, 5; and GTP, 0.5; pH 7.2 adjusted with $\mathrm{CsOH}$; and osmolality $300 \mathrm{mOsm}$. Patch-clamp recordings were performed in a bath solution containing (in $\mathrm{mM}$ ): sodiummethanesulfonate, $125 ; \mathrm{KCl}, 3 ; \mathrm{MgCl}_{2}, 1 ; \mathrm{CaCl}_{2}, 5 ; 4$-aminopyridine, 4; tetraethylammonium chloride , 20; HEPES, 10; glucose, 10 (pH 7.4, $315 \mathrm{mOsmol})$. Tight-seal, whole-cell recordings were obtained at room temperature $\left(21-24^{\circ} \mathrm{C}\right)$ according to the standard techniques. Membrane currents were recorded using a patch-clamp amplifier (Axopatch 200B, Molecular Devices, Sunnyvale, USA or EPC9, HEKA Elektronik, Lambrecht, Germany). Series resistance compensation was employed to improve the voltage-clamp control $(>80 \%)$ so that the maximal residual voltage error did not exceed $1.5 \mathrm{mV}$. Voltage-clamp recordings were corrected online for a liquid junction potential of $10 \mathrm{mV}$. Whole-cell $\mathrm{Ca}^{2+}$ currents were elicited with depolarizing voltage steps to $-10 \mathrm{mV}$. The magnitude of $I_{\mathrm{CaT}}$ was quantified by analysing the transient component of the resulting current traces.

The voltage dependence of activation and inactivation was characterized using standard voltage step protocols (Fig. 2a). The voltage-dependent activation of the $\mathrm{Ca}^{2+}$ conductance was fit by the product of a Boltzmann function, reflecting voltage-dependent activation equation (1), and the general constant field equation (2):

$$
\begin{gathered}
g_{\mathrm{Ca}}(V)=A_{1}+\frac{A_{0}-A_{1}}{1+e^{\left(V_{1 / 2}-V\right) / k}} \\
I_{\mathrm{Ca}}(V)=g_{\mathrm{Ca}}(V) \frac{4 F^{2}}{R T} V\left(\frac{\left[\mathrm{Ca}^{2+}\right]_{\text {in }}-\left[\mathrm{Ca}^{2+}\right]_{\text {out }} e^{\left(-\frac{2 V F}{R T}\right)}}{1-e^{\left(-\frac{2 V F}{R T}\right)}}\right)
\end{gathered}
$$

where $I_{\mathrm{Ca}}(V)$ denotes the $\mathrm{Ca}^{2+}$ current and $g_{\mathrm{Ca}}(V)$ the $\mathrm{Ca}^{2+}$ conductance amplitude, respectively, at the membrane potential $V$ as set by the command voltage $V .\left[\mathrm{Ca}^{2+}\right]_{\text {in }}$ and $\left[\mathrm{Ca}^{2+}\right]_{\text {out }}$ correspond to internal and external $\mathrm{Ca}^{2+}$ concentration, respectively. The values $V_{1 / 2}$ (membrane potential at half-maximal inactivation or activation), $A_{0}$ and $A_{1}$ (maximal and minimal conductance, respectively) were determined by the fitting procedure. $F$ is Faraday's constant, $R$ is the gas constant and $T$ is the temperature at which the measurements were conducted $\left(22^{\circ} \mathrm{C}\right.$ on average). The conductance $g_{\mathrm{Ca}}$ for each potential was derived, normalized to $A_{0}$ and averaged for all cells of the same group. The voltage dependence of inactivation was derived by converting peak current to $g_{\mathrm{Ca}}$ and fitting these values with equation (1).

Luciferase assay. Transfection of the NG108-15 cells was carried out using lipofectamine (Invitrogen) following the manufacturer's protocol. For each well (48-well tissue culture plates; $80 \%$ confluency), $0.5 \mu \mathrm{g} \mathrm{Ca} \mathrm{C}_{V} 3.2$ luciferase reporter plasmid, $0.0125 \mu \mathrm{g}$ pRL-TK (Promega) and $0.5 \mu \mathrm{l}$ lipofectamine were mixed with $25 \mu \mathrm{l} \mathrm{serum}$-free medium. The mixture was incubated for $20 \mathrm{~min}$ at room temperature and then added to the appropriate wells. Cells were grown in serum-free culture medium at $37^{\circ} \mathrm{C}$ and $5 \% \mathrm{CO}_{2}$. After $16 \mathrm{~h}$, the serum-free medium was replaced by serum-containing medium and the cells were used for experiments $36 \mathrm{~h}$ after transfection.

Renilla luciferase was used to normalize the transfection efficiency data, and a Dual Luciferase Reporter Assay System was used according to the manufacturer's specifications (Promega). Renilla and firefly luciferase activities were determined using the Glomax Luminometer (Promega). The results are given as firefly/Renilla relative light units if not indicated otherwise.

Chromatin immunoprecipitation assays. ChIP on mouse hippocampal tissue. Mice were decapitated under deep isoflurane anaesthesia (Forene). Hippocampi were removed quickly, snap frozen and stored at $-80^{\circ} \mathrm{C}$ until further processing Samples for ChIP experiments were prepared using the SimpleChIP Plus Enzymatic chromatin IP kit (Cell Signaling Technology; \#9005) according to the manufacturer's protocol with $5 \mu \mathrm{g}$ anti-MTF1 (C-19X, SC26844X, Santa Cruz, CA) and $2 \mu \mathrm{g}$ anti-IgG (Cell Signaling Technology; \#2729). The recovered DNA was analysed by PCR with primers spanning the $\mathrm{Zn}^{2+}$-sensitive MRE (forward: $5^{\prime}$-CGCGCGAGAAAAGGAGGGGG- $3^{\prime}$ and reverse: $3^{\prime}$-GCTCGCAGGGATGCTT GGA- $3^{\prime}$ ) and with primers located in the $\mathrm{Ca}_{3} 3.2$ promoter region, but lacking a MRE (forward: 5'-GAAGGGAGATTCAGCGACAT- $3^{\prime}$ and reverse: $5^{\prime}$-CCAATTG TACTGGGGCAGTC- $3^{\prime}$ ). PCR amplification in a $25-\mu \mathrm{l}$ reaction included $1 \mu \mathrm{l}$ immunoprecipitated DNA, 10 pmol of each primer and EconoTaq Plus Green $1 \times$ Master Mix (Lucigen Corporation, Middleton, WI). Reactions were amplified for 35 cycles at $94^{\circ} \mathrm{C}$ for $30 \mathrm{~s}, 58^{\circ} \mathrm{C}$ for $30 \mathrm{~s}$ and $72^{\circ} \mathrm{C}$ for $45 \mathrm{~s}$, followed by a final extension step at $72{ }^{\circ} \mathrm{C}$ for $10 \mathrm{~min}$. PCR products were analysed on a $2 \%$ agarose gel.

ChIP on NG108-15 cells. NG108-15 cells (six wells; $100 \%$ confluency) were cross-linked with $1 \%$ formaldehyde for $10 \mathrm{~min}$ at $37^{\circ} \mathrm{C}$. Cells were washed twice in cold PBS containing protease inhibitors (Complete Protease Inhibitor Cocktail Tablets; Roche), lysed in $200 \mu \mathrm{l}$ SDS lysis buffer (1\% SDS; $10 \mathrm{mM}$ EDTA; $50 \mathrm{mM}$ Tris, $\mathrm{pH} 8.1$ with protease inhibitors) and incubated on ice for $10 \mathrm{~min}$. Lysates were sonicated using an Ultrasonic Processor UP50H (Hielscher Ultrasound Technology, Germany), with four sets of 10 -s pulses at $50 \%$ of maximum power. Samples were centrifuged at 13,000 r.p.m. for $10 \mathrm{~min}$ at $4{ }^{\circ} \mathrm{C}$ and the supernatant was diluted 10 -fold in ChIP dilution buffer (0.01\% SDS; $1.1 \%$ Triton X-100; $1.2 \mathrm{mM}$ EDTA; $16.7 \mathrm{mM}$ Tris, $\mathrm{pH} 8.1$; and $167 \mathrm{mM} \mathrm{NaCl}$ with protease inhibitors). Next, samples were incubated overnight at $4{ }^{\circ} \mathrm{C}$ with $5 \mu \mathrm{g}$ anti-MTF1 (C-19X, SC26844X, Santa Cruz, CA). Rabbit-IgG incubations (Cell Signaling Technology; \#2729) were included as control for the immunoprecipitation. Further processing of the ChIP samples was performed using the SimpleChIP Plus Enzymatic chromatin IP kit (Cell Signaling Technology; \#9005) as described above.

Viral vector production. Recombinant AAV1/2 genomes were generated by largescale triple transfection of HEK293-AAV cells. The rAAV plasmid, helper plasmids encoding rep and cap genes (pRV1 and pH21), and adenoviral helper pF $\Delta 6$ (Stratagene, La Jolla, USA) were transfected using standard $\mathrm{CaPO}_{4}$ transfection. Cells were collected $\sim 60 \mathrm{~h}$ following transfection. Cell pellets were lysed in the presence of $0.5 \%$ sodium deoxycholate (Sigma) and $50 \mathrm{U} \mathrm{ml}^{-1}$ Benzonase endonuclease (Sigma). rAAV viral particles were purified from the cell lysate by HiTrap heparin column purification (GE Healthcare), and then concentrated to a final stock volume of $400 \mu \mathrm{l}$ using Amicon Ultra Centrifugal Filters (Millipore). Purity of the viruses was validated by coomassie blue staining of SDS-polyacrylamide gels. Functional titres (transducing units) of the fluorescent protein vectors were determined by transduction of cultured primary neurons.

Animal experiments. Infusion of $A A V$ vectors. Mice and rats were housed under a $12 \mathrm{~h} \mathrm{light/dark} \mathrm{cycle} \mathrm{with} \mathrm{food} \mathrm{and} \mathrm{water} \mathrm{ad} \mathrm{libitum.} \mathrm{All} \mathrm{experiments} \mathrm{were} \mathrm{per-}$ formed in accordance with the guidelines of the European Union and the University of Bonn Medical Center Animal Care Committee. Adult male mice ( 50 days, $>20 \mathrm{~g})$ were obtained from Charles River $(\mathrm{C} 57 \mathrm{Bl} / 6-\mathrm{N})$ and were anesthetized with $6 \mathrm{mg} \mathrm{kg}^{-1}$ xylazine (Rompun; Bayer) plus $90-120 \mathrm{mg} \mathrm{kg}^{-1}$ ketamine, intraperitoneal (i.p.) (Ketavet; Pfizer). Intracerebral injection of viral particles in the left and right CA1 hippocampal region was performed stereotactically at the coordinates (in $\mathrm{mm}$ ) -2 posterior, $-2 / 2$ lateral and 1.7 ventral relative to bregma. Holes the size of the injection needle were drilled into the skull, and $1 \mu \mathrm{l}$ of viral suspension containing $\sim 10^{8}$ transducing units was injected using a $10 \mu \mathrm{l}$ Hamilton syringe at a rate of $100 \mathrm{nlmin}^{-1}$ using a microprocessor-controlled mini-pump (World Precision Instruments). After injection, the needle was left in place for $5 \mathrm{~min}$ before withdrawal. The needle was then slowly withdrawn and the incision closed.

Near-infrared in vivo imaging. MTF1 overexpression. Mice were injected with rAAV-Ca 3.2 -iRFP particles as described above. Two weeks after injection, mice were anesthetized, the skull was exposed and holes were drilled at the same location for subsequent rAAV-Syn-MTF1-IRES-Venus or rAAV-Syn-Venus injection. Just before injection, basal iRFP values were measured through the skull. Three weeks after injection of viruses harbouring MTF1- or Venus-expressing constructs, iRFP values were again determined. 
$\mathrm{Zn}^{2+}$ injection. Animals were injected with $\mathrm{rAAV}-\mathrm{Ca} a_{V} 3.2$-iRFP particles in the hippocampal CA1 region and analysed for their basal iRFP levels 3 weeks after injection. Next, they were injected with $1 \mu \mathrm{l} 100 \mu \mathrm{M} \mathrm{ZnCl}_{2}$ or $1 \mu \mathrm{l} 0.9 \% \mathrm{NaCl}$ in the same holes as used for the rAAV particles. Animals were imaged again 3 days after injection.

Near-infrared imaging was performed with a Pearl Impulse Small Animal Imaging System (Li-COR Biosciences GmbH). The iRFP signal was determined using a highly sensitive charged-coupled device camera. Excitation and emission wavelengths were fixed at 690 and $710 \mathrm{~nm}$, respectively. Pictures were analysed using the Pearl Impulse Image Studio Software v3.1 (Li-COR Biosciences GmbH). Fluorescent signals were normalized to background levels and quantified by placing two round regions of interest (Fig. 6e) above the hippocampal region ${ }^{39}$. Fluorescent signals are presented as arbitrary units (a.u.).

At the end of the in vivo imaging experiments, mice were decapitated under deep isoflurane (Forene) anesthesia. Brains were removed and fixed in formaldehyde overnight. Coronal brain slices $(30 \mu \mathrm{m})$ were made on a vibratome (Leica), mounted on slides (Histobond, Marienfelde Germany) and imaged on the Odyssey infrared imaging system (Li-COR Biosciences $\mathrm{GmbH}$ ). Only animals with hippocampal CA1 staining (Fig. 6f) were included in the in vivo imaging analysis.

EEG-video monitoring. The electrographic features of Venus- and MTF1 $\Delta C$ injected animals after pilocarpine-SE were analysed with a telemetric EEG/videomonitoring system (Data Science International) as described previously ${ }^{13,41}$. Mice were implanted with EEG electrodes directly after the viral injection (described above), when the animals were still narcotized. The transmitter was placed subcutaneously on the right abdominal side and stainless screws were used as electrodes and positioned in the two holes used for the viral injection $(2 \mathrm{~mm}$ posterior and $2 \mathrm{~mm}$ lateral to Bregma). EEG recording with a sampling rate of $1 \mathrm{kHz}$ was started directly after the implantation procedure. Two weeks after the implantation, animals experienced pilocarpine-SE. Monitoring was performed continuously until day 20 after SE. EEG recordings were analysed using NeuroScore v2.1 (DSI) software with the following parameters: a threshold value between 100 and $5,000 \mu \mathrm{V}$; a spike duration between 5 and $70 \mathrm{~ms}$; a spike interval between 0.005 and $1 \mathrm{~s}$; a minimum train duration of $5 \mathrm{~s}$; and a minimum number of spikes per event of 10 . These parameters were verified by analysing two animals manually for the whole timeframe. All positive events (seizures) of the two animals were identified using these parameters. The output of all animals was checked manually for false-positive events (for example, artefacts) and all false-positive events were deleted from the output files. From concurrent video recordings, all seizures were classified as described previously ${ }^{41}$.

Pilocarpine-SE in mice and rats. As described previously ${ }^{41}$, adult male C57Bl/ 6-N mice received a low dose of scopolamine methyl nitrate $\left(1 \mathrm{mg} \mathrm{kg}^{-1}\right.$, subcutaneous (s.c.); Sigma) $20 \mathrm{~min}$ before the administration of pilocarpine hydrochloride ( $335 \mathrm{mg} \mathrm{kg}^{-1}$, s.c.; Sigma). Forty minutes after SE onset, the mice received $4 \mathrm{mg} \mathrm{kg}^{-1}$ s.c. diazepam (Ratiopharm). Sham-control animals were treated identically, but received saline instead of pilocarpine.

Adult male Sabra rats (150-200 g) were kept in the animal facility of Hebrew University and Hadassah School of Medicine. All the experiments were approved by the local institution's ethical committee. Rats were injected with scopolamine methyl nitrate $\left(1 \mathrm{mg} \mathrm{kg}^{-1}\right.$, s.c; Sigma). Thirty minutes afterwards, SE was induced with a single dose of pilocarpine ( $350 \mathrm{mg} \mathrm{kg}^{-1}$ (i.p.); Sigma). SE was terminated after $2 \mathrm{~h}$ by diazepam (Ratiopharm; $0.1 \mathrm{mg} \mathrm{kg}^{-1}$ (i.p.)).

$\mathbf{Z n}^{\mathbf{2}+}$ imaging in rat brain slices. Pilocarpine-injected rats were decapitated under isoflurane anesthesia at different time points after the termination of SE. The brains were rapidly extracted and immediately frozen in liquid nitrogen and were stored at $-80^{\circ} \mathrm{C}$. Either transversal $(2-5.5 \mathrm{~mm}$ below the inter-auricular plane, containing the ventral part of the hippocampus) or saggital (1-3.5 mm laterally to the inter-hemispheric plane, containing the dorsal hippocampus) slices, $20-\mu \mathrm{m}$ wide, were cut in a cryotome and placed on glass slides. For the staining we used 1 of every 10 slices, $200 \mu \mathrm{m}$ apart from each other, for a total of 15 transverse and 12 sagittal slices for each hemisphere.

For visualization of chelatable $\mathrm{Zn}^{2+}$, fresh frozen brain slices were examined under a fluorescent microscope (Olympus BX60, Germany; excitation filter $330-385 \mathrm{~nm}$, emission filter $420 \mathrm{~nm}$ ), at least $30 \mathrm{~min}$ after the preparation. TFL-Zn (Sigma), $250 \mu \mathrm{M}$ in saline, was applied to the slices, immediately before the microscopic examination, for $30 \mathrm{~s}$ and washed with saline. Stained CA1 hippocampal cells were counted by use of a gridded microscope lens (with calculated area of $0.05 \mathrm{~mm}^{2}$ in high-power field). The density of $\mathrm{Zn}^{2+}$-stained neurons was defined as the number of $\mathrm{Zn}^{2+}$-stained neurons counted in a $0.05-\mathrm{mm}^{2}$ area of the slice (grid surface) at high-power field.

Human TLE patients and mRNA expression analyses. For gene expression analyses, we used human hippocampal biopsy tissue from patients with hippocampal sclerosis $(n=79)$ versus patients with lesion-associated (low-grade neoplasms or dysplasia; $n=35$ ) chronic TLE, who underwent surgical treatment in the Epilepsy Surgery Program at the University of Bonn Medical Center due to pharmacoresistance. In all patients, presurgical evaluation using a combination of non-invasive and invasive procedures revealed that seizures originated in the mesial temporal lobe ${ }^{42}$. All procedures were conducted in accordance with the Declaration of Helsinki and approved by the Ethics Committee of the University of Bonn Medical Center. Informed written consent was obtained from all patients. Clinical characteristics per subgroup are described in Supplementary Table 3. mRNA analyses for $\mathrm{Ca}_{\mathrm{V}} 3.2$ and MTF1 were carried out analogous to a procedure described elsewhere in detail ${ }^{43}$. Briefly, RNA from biopsies representing all hippocampal subfields served to generate $750 \mathrm{ng}$ cRNA used for hybridization on Human HT-12 v3 Expression BeadChips with Illumina Direct Hybridization Assay Kit (Illumina, San Diego, CA) according to standard procedures. We extracted data for $\mathrm{Ca}_{\mathrm{V}} 3.2$ and MTF1 analysed by Illumina's GenomeStudio Gene Expression Module and normalized using Illumina BeadStudio software suite by quantile normalization with background subtraction.

Statistical analysis. Statistical analyses were performed with GraphPad Prism 6.05 software (GraphPad Software). Sample size ( $n$ ) per experiment was calculated using power analysis, with parameters set within the accuracy of the respective experiment. Student's $t$-tests and repeated measures analysis of variance followed by Bonferroni's multiple comparisons or Tukey's multiple comparisons tests were used to evaluate the statistical significance of the results. Values were considered significantly at $P<0.05$. All results are plotted as mean \pm s.e.m. All electrophysiological and animal experiments were conducted in a randomized and blinded fashion. All in vitro experiments were independently repeated at least two times.

\section{References}

1. Hauser, W. A., Annegers, J. F. \& Kurland, L. T. Incidence of epilepsy and unprovoked seizures in Rochester, Minnesota: 1935-1984. Epilepsia 34, 453-468 (1993).

2. Murray, C. J., Lopez, A. D. \& Jamison, D. T. The global burden of disease in 1990: summary results, sensitivity analysis and future directions. Bull. World Health Organ. 72, 495-509 (1994).

3. Kale, R. Bringing epilepsy out of the shadows. BMJ 315, 2-3 (1997).

4. Wiebe, S., Blume, W. T., Girvin, J. P. \& Eliasziw, M. A randomized, controlled trial of surgery for temporal-lobe epilepsy. N. Engl. J. Med. 345, 311-318 (2001).

5. Pitkanen, A. \& Engel, Jr. J. Past and present definitions of epileptogenesis and its biomarkers. Neurotherapeutics 11, 231-241 (2014).

6. Bernard, C. et al. Acquired dendritic channelopathy in temporal lobe epilepsy. Science 305, 532-535 (2004).

7. Waxman, S. G. Transcriptional channelopathies: an emerging class of disorders. Nat. Rev. Neurosci. 2, 652-659 (2001).

8. Richichi, C. et al. Mechanisms of seizure-induced 'transcriptional channelopathy' of hyperpolarization-activated cyclic nucleotide gated ( $\mathrm{HCN})$ channels. Neurobiol. Dis. 29, 297-305 (2008).

9. Beck, H. \& Yaari, Y. Plasticity of intrinsic neuronal properties in CNS disorders. Nat. Rev. Neurosci. 9, 357-369 (2008).

10. Sanabria, E. R., Su, H. \& Yaari, Y. Initiation of network bursts by $\mathrm{Ca} 2+-$ dependent intrinsic bursting in the rat pilocarpine model of temporal lobe epilepsy. J. Physiol. 532, 205-216 (2001).

11. Yaari, Y., Yue, C. \& Su, H. Recruitment of apical dendritic T-type $\mathrm{Ca}^{2+}$ channels by backpropagating spikes underlies de novo intrinsic bursting in hippocampal epileptogenesis. J. Physiol. 580, 435-450 (2007).

12. Su, H. et al. Upregulation of a T-type $\mathrm{Ca}^{2+}$ channel causes a long-lasting modification of neuronal firing mode after status epilepticus. J. Neurosci. 22, 3645-3655 (2002).

13. Becker, A. J. et al. Transcriptional upregulation of Cav3.2 mediates epileptogenesis in the pilocarpine model of epilepsy. J. Neurosci. 28, 13341-13353 (2008).

14. Suh, S. W., Thompson, R. B. \& Frederickson, C. J. Loss of vesicular zinc and appearance of perikaryal zinc after seizures induced by pilocarpine. Neuroreport 12, 1523-1525 (2001).

15. Traboulsie, A. et al. Subunit-specific modulation of T-type calcium channels by zinc. J. Physiol. 578, 159-171 (2007).

16. Ekstein, D. et al. Zinc induces long-term upregulation of T-type calcium current in hippocampal neurons in vivo. J. Physiol. 590, 5895-5905 (2012).

17. Imanishi, T. et al. Increased response to high KCl-induced elevation in the intracellular- $\mathrm{Ca}^{2+}$ concentration in differentiated NG108-15 cell and the inhibitory effect of the L-type $\mathrm{Ca}^{2+}$ channel blocker, calciseptine. Neurochem. Res. 31, 33-40 (2006).

18. Frederickson, C. J., Klitenick, M. A., Manton, W. I. \& Kirkpatrick, J. B. Cytoarchitectonic distribution of zinc in the hippocampus of man and the rat. Brain Res. 273, 335-339 (1983).

19. Assaf, S. Y. \& Chung, S. H. Release of endogenous $\mathrm{Zn} 2+$ from brain tissue during activity. Nature 308, 734-736 (1984).

20. van Loo, K. M. et al. Transcriptional regulation of T-type calcium channel $\mathrm{Ca}_{\mathrm{v}}$ 3.2: bi-directionality by early growth response 1 (Egr1) and repressor 
element 1 (RE-1) protein-silencing transcription factor (REST). J. Biol. Chem. 287, 15489-15501 (2012).

21. Choi, S. \& Bird, A. J. Zinc'ing sensibly: controlling zinc homeostasis at the transcriptional level. Metallomics 6, 1198-1215 (2014).

22. Andrews, G. K. Cellular zinc sensors: MTF-1 regulation of gene expression. Biometals 14, 223-237 (2001).

23. Larochelle, O., Stewart, G., Moffatt, P., Tremblay, V. \& Seguin, C. Characterization of the mouse metal-regulatory-element-binding proteins, metal element protein-1 and metal regulatory transcription factor-1. Biochem. J. 353, 591-601 (2001).

24. Lavoie, N. et al. Extracellular chelation of zinc does not affect hippocampal excitability and seizure-induced cell death in rats. J. Physiol. 578, 275-289 (2007).

25. Wimmer, U., Wang, Y., Georgiev, O. \& Schaffner, W. Two major branches of anti-cadmium defense in the mouse: MTF-1/metallothioneins and glutathione. Nucleic Acids Res. 33, 5715-5727 (2005).

26. Kagi, J. H. \& Valee, B. L. Metallothionein: a cadmium- and zinc-containing protein from equine renal cortex. J. Biol. Chem. 235, 3460-3465 (1960).

27. Heuchel, R. et al. The transcription factor MTF-1 is essential for basal and heavy metal-induced metallothionein gene expression. EMBO J. 13, 2870-2875 (1994).

28. Aida, T. et al. Cloning-free CRISPR/Cas system facilitates functional cassette knock-in in mice. Genome Biol. 16, 87 (2015).

29. Cuajungco, M. P. \& Lees, G. J. Nitric oxide generators produce accumulation of chelatable zinc in hippocampal neuronal perikarya. Brain Res. 799, 118-129 (1998).

30. Kroncke, K. D. et al. Nitric oxide destroys zinc-sulfur clusters inducing zinc release from metallothionein and inhibition of the zinc finger-type yeast transcription activator LAC9. Biochem. Biophys. Res. Commun. 200, 1105-1110 (1994).

31. Liu, J. et al. Oxidative stress mediates hippocampal neuron death in rats after lithium-pilocarpine-induced status epilepticus. Seizure 19, 165-172 (2010).

32. Vallee, B. L. \& Falchuk, K. H. The biochemical basis of zinc physiology. Physiol. Rev. 73, 79-118 (1993).

33. Cahoon, L. The curious case of clioquinol. Nat. Med. 15, 356-359 (2009).

34. Bladen, C. et al. Characterization of novel cannabinoid based T-type calcium channel blockers with analgesic effects. ACS Chem. Neurosci. 6, 277-287 (2014).

35. Adams, T. K., Saydam, N., Steiner, F., Schaffner, W. \& Freedman, J. H. Activation of gene expression by metal-responsive signal transduction pathways. Environ. Health Perspect. 110, 813-817 (2002).

36. Baxendale, S. et al. Identification of compounds with anti-convulsant properties in a zebrafish model of epileptic seizures. Dis. Model Mech. 5, 773-784 (2012).

37. Beckstette, M., Homann, R., Giegerich, R. \& Kurtz, S. Fast index based algorithms and software for matching position specific scoring matrices. $B M C$ Bioinformatics 7, 389 (2006).

38. Matys, V. et al. TRANSFAC and its module TRANSCompel: transcriptional gene regulation in eukaryotes. Nucleic Acids Res. 34, D108-D110 (2006)

39. Kulbida, R. et al. Molecular imaging reveals epileptogenic $\mathrm{Ca}^{2+}$-channel promoter activation in hippocampi of living mice. Brain Struct. Funct. 220, 3067-3073 (2015)
40. Zurner, M., Mittelstaedt, T., Tom Dieck, S., Becker, A. \& Schoch, S. Analyses of the spatiotemporal expression and subcellular localization of liprin-alpha proteins. J. Comp. Neurol. 519, 3019-3039 (2011).

41. Pitsch, J. et al. Functional role of mGluR1 and mGluR4 in pilocarpine-induced temporal lobe epilepsy. Neurobiol. Dis. 26, 623-633 (2007).

42. Kral, T. et al. Preoperative evaluation for epilepsy surgery (Bonn Algorithm). Zentralbl. Neurochir. 63, 106-110 (2002).

43. Pernhorst, K. et al. TLR4, ATF-3 and IL8 inflammation mediator expression correlates with seizure frequency in human epileptic brain tissue. Seizure 22, 675-678 (2013).

\section{Acknowledgements}

Our work is supported by Deutsche Forschungsgemeinschaft (SFB 1089) (K.M.J.v.L., A.J.B., H.B. and S.S.), BMBF \& MOST, GIF (A.J.B., S.S. and Y.Y.), DIP (H.B. and Y.Y.), ESF EuroEpinomics (A.J.B., K.M.J.v.L.), the European Union's Seventh Framework Programme (FP7/2007-2013) under grant agreement no. 602102 (EPITARGET; A.J.B., S.S. and H.B.), Else Kröner-Fresenius-Foundation (A.J.B.), Fritz Thyssen Foundation (Ref. 10.15.2.022 MN; A.J.B.) as well as the BONFOR program of the University of Bonn Medical Center. We thank Katharina Pernhorst and Per Hoffmann for scientific discussions, Sabine Normann, Lioba Dammer, Vanessa Schmitt, Daniela Frangenberg and Sabine Opitz for excellent technical assistance and Carl Seguin (Québec) and Guy J. Rosnan (Seattle) for providing plasmids and critically discussing our experiments.

\section{Author contributions}

K.M.J.v.L., Y.Y. and A.J.B. conceived and planned the study; K.M.J.v.L. performed molecular and cellular experiments; C.S. and T.O. performed electrophysiological experiments; K.M.J.v.L. and R.K. performed viral injections and in vivo imaging; D.E. and A.D. performed TFL-Zn staining; J.P. performed EEG-video monitoring; H.U. and A.J.B. organized the human studies; H.B., Y.Y. and S.S. contributed to study design and analysis; K.M.J.v.L., Y.Y. and A.J.B. wrote the manuscript.

\section{Additional information}

Supplementary Information accompanies this paper at http://www.nature.com/ naturecommunications

Competing financial interests: The authors declare no competing financial interests.

Reprints and permission information is available online at http://npg.nature.com/ reprintsandpermissions/

How to cite this article: van Loo, K. M. J. et al. Zinc regulates a key transcriptional pathway for epileptogenesis via metal-regulatory transcription factor 1. Nat. Commun. 6:8688 doi: 10.1038/ncomms9688 (2015).

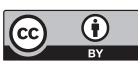

This work is licensed under a Creative Commons Attribution 4.0 International License. The images or other third party material in this article are included in the article's Creative Commons license, unless indicated otherwise in the credit line; if the material is not included under the Creative Commons license, users will need to obtain permission from the license holder to reproduce the material. To view a copy of this license, visit http://creativecommons.org/licenses/by/4.0/ 